\title{
Steps toward Determination of the Size and Structure of the Broad\#Line Region in Active Galactic Nuclei. XV. Long\#Term Optical Monitoring of NGC 5548
}

\section{Citation}

Peterson, B. M., A. J. Barth, P. Berlind, R. Bertram, K. Bischoff, N. G. Bochkarev, A. N. Burenkov, et al. 1999. "Steps Toward Determination of the Size and Structure of the Broad\#Line Region in Active Galactic Nuclei. XV. Long\#Term Optical Monitoring of NGC 5548." The Astrophysical Journal 510 (2) (January 10): 659-668. doi:10.1086/306604.

\section{Published Version}

doi:10.1086/306604

\section{Permanent link}

http://nrs.harvard.edu/urn-3:HUL.InstRepos:30248642

\section{Terms of Use}

This article was downloaded from Harvard University's DASH repository, and is made available under the terms and conditions applicable to Other Posted Material, as set forth at http:// nrs.harvard.edu/urn-3:HUL.InstRepos:dash.current.terms-of-use\#LAA

\section{Share Your Story}

The Harvard community has made this article openly available.

Please share how this access benefits you. Submit a story.

Accessibility 


\title{
STEPS TOWARD DETERMINATION OF THE SIZE AND STRUCTURE OF THE BROAD-LINE REGION IN ACTIVE GALACTIC NUCLEI. XV. LONG-TERM OPTICAL MONITORING OF NGC 5548
}

B. M. Peterson, ${ }^{1}$ A. J. Barth, ${ }^{2}$ P. Berlind, ${ }^{3}$ R. Bertram,,${ }^{1,4}$ K. Bischoff, ${ }^{5}$ N. G. Bochkarev, ${ }^{6}$ A. N. Burenkov, ${ }^{7}$ F.-Z. Cheng, ${ }^{8}$ M. Dietrich, ${ }^{9}$ A. V. Filippenko, ${ }^{2}$ E. Giannuzzo, ${ }^{10}$ L. C. Ho, ${ }^{3}$ J. P. HuChra, ${ }^{3}$ J. Hunley, ${ }^{1}$

S. Kaspi, ${ }^{11}$ W. Kollatschny, ${ }^{5}$ D. C. Leonard, ${ }^{2}$ YU. F. Malkov, ${ }^{12}$ T. Matheson, ${ }^{2}$ M. Mignoli,${ }^{13}$

B. Nelson,,${ }^{14}$ P. Papaderos, ${ }^{5}$ J. Peters, ${ }^{3,15}$ R. W. Pogge, ${ }^{1}$ V. I. Pronik, ${ }^{12,16}$ S. G. Sergeev, ${ }^{12,16}$

E. A. Sergeeva, ${ }^{12,16}$ A. I. Shapovalova, ${ }^{7}$ G. M. StirPe, ${ }^{13}$ S. Tokarz ${ }^{3}$ R. M. Wagner, ${ }^{1,4}$

I. WANDERS, ${ }^{1,17}$ J.-Y. WeI ${ }^{18}$ B. J. WILKeS, ${ }^{3}$ H. WU, ${ }^{18}$ S.-J. XUE, ${ }^{8}$ AND Z.-L. ZOU ${ }^{18}$

Received 1998 March 16; accepted 1998 August 14

\begin{abstract}
We present the results of $3 \mathrm{yr}$ of ground-based observations of the Seyfert 1 galaxy NGC 5548, which, combined with previously reported data, yield optical continuum and broad-line $\mathrm{H} \beta$ light curves for a total of $8 \mathrm{yr}$. The light curves consist of over 800 points, with a typical spacing of a few days between observations. During this 8 yr period, the nuclear continuum has varied by more than a factor of 7 , and the $\mathrm{H} \beta$ emission line has varied by a factor of nearly 6 . The $\mathrm{H} \beta$ emission line responds to continuum variations with a time delay or lag of $\sim 10-20$ days, the precise value varying somewhat from year to year. We find some indications that the lag varies with continuum flux in the sense that the lag is larger when the source is brighter.
\end{abstract}

Subject headings: galaxies: active — galaxies: individual (NGC 5548) - galaxies: nuclei galaxies: Seyfert

\section{INTRODUCTION}

The observed time delays between continuum and emission-line flux variations can be used to determine the size and structure of the broad-line region (BLR) in active

\footnotetext{
${ }^{1}$ Department of Astronomy, The Ohio State University, 174 West 18th Avenue, Columbus, OH 43210-1106; peterson, pogge@astronomy.ohiostate.edu, jhunley@elmers.com.

${ }^{2}$ Department of Astronomy, University of California at Berkeley, Berkeley, CA 94720-3411; abarth, afilippenko, dleonard, tmatheson@ astro.berkeley.edu.

${ }^{3}$ Harvard-Smithsonian Center for Astrophysics, 60 Garden Street, Cambridge, MA 02138; pberlind, lho, huchra, belinda@cfa.harvard.edu.

${ }^{4}$ Mailing address: Lowell Observatory, 1400 West Mars Hill Road, Flagstaff, AZ 86001; rayb@lowell.edu, rmw@altair.lowell.edu.

${ }^{5}$ Universitäts-Sternwarte Göttingen, Geismarlandstrasse 11, D-37083 Göttingen, Germany; bischoff, papade@uni-sw.gwdg.de, wkollat@ gwdg.de.

${ }^{6}$ Sternberg Astronomical Institute, University of Moscow, Universitetskij Prospect 13, Moscow 119899, Russia; boch@astronomy.msk.su.

${ }^{7}$ Special Astrophysical Observatory, Russian Academy of Sciences, Nizhnij Arkhyz, Karachai-Cherkess Republic, 357147, Russia; ashap@sao.ru.

${ }^{8}$ Center for Astrophysics, University of Science and Technology of China, Hefei, Anhui, People's Republic of China; fzhen@ustc.edu.cn.

${ }^{9}$ Landessternwarte Heidelberg, Konigstuhl, D-69117 Heidelberg, Germany; mdietric@mail.lsw.uni-heidelberg.de.

${ }^{10}$ Department of Physical Sciences, University of Hertfordshire, College Lane, Hatfield, Herts. AL10 9AB, England, UK; ester@star.herts.ac.uk.

${ }^{11}$ School of Physics and Astronomy and the Wise Observatory, The Raymond and Beverly Sackler Faculty of Exact Sciences, Tel Aviv University, Tel Aviv 69978, Israel; shai@wise.tau.ac.il.

12 Crimean Astrophysical Observatory, P/O Nauchny, 334413 Crimea, Ukraine; vpronik, sergeev, selena@crao.crimea.ua.

${ }^{13}$ Osservatorio Astronomico di Bologna, Via Zamboni 33, I-40126 Bologna, Italy; mignoli, stirpe@ astbo3.bo.astro.it.

${ }^{14}$ Department of Physics and Astronomy, University of California at Los Angeles, Math-Science Building, Los Angeles, CA 90024; nelson@astro.ucla.edunelson@astro.ucla.edu.

15 Deceased.

${ }^{16}$ Also: Isaac Newton Institute of Chile, Crimean Branch.

${ }^{17}$ Mailing address: Mercatorpad 4, bus 401, 3000 Leuven, Belgium Email:xenu@xs4all.nl.

${ }^{18}$ Beijing Astronomical Observatory, Beijing 100080, People's Republic of China; wu@bac.pku.edu.cn, zouzl@sun.ihep.ac.cn.
}

galactic nuclei (AGNs) through the process known as "reverberation mapping" (Blandford \& McKee 1982). It is assumed that the continuum light curve $C(t)$ and emissionline light curve $L(t)$ are related as

$$
L(t)=\int \Psi(\tau) C(t-\tau) d \tau,
$$

where $\Psi(t)$ is the "transfer function," which depends on the geometry and reprocessing physics of the BLR. The aim of reverberation mapping is to use the observed light curves $C(t)$ and $L(t)$ to solve for $\Psi(\tau)$ and thus infer the geometry of the BLR. On account of the amount and quality of data required to determine $\Psi(\tau)$ uniquely, reverberationmapping studies are still in a state of relative infancy, and it is far more common to obtain only a cross-correlation function $(\mathrm{CCF}) F_{\mathrm{CCF}}(\tau)$ between the continuum and emissionline light curves. By convolving equation (1) with $C(t)$, it is simple to show that

$$
F_{\mathrm{CCF}}(\tau)=\int \Psi\left(\tau^{\prime}\right) F_{\mathrm{ACF}}\left(\tau-\tau^{\prime}\right) d \tau^{\prime},
$$

where $F_{\mathrm{ACF}}(\tau)$ is the continuum autocorrelation function (Penston 1991; Peterson 1993). It can also be shown that the centroid of the CCF is a measure of the emissivityweighted mean radius of the variable part of the BLR (Koratkar \& Gaskell 1991). Therefore, even a relatively unsophisticated time-series analysis can give us an appropriate scale length for the BLR by simply measuring the time-delayed response of an emission line to continuum variations and interpreting this time delay as due to light travel-time effects within the BLR.

Over the last decade, high-intensity spectroscopic monitoring programs have led to determination of characteristic emission-line response times for about two dozen mostly low-luminosity AGNs (see Netzer \& Peterson 1997 for a recent review). The most extensive of these various efforts is a continuing program of optical ground-based monitoring of the bright Seyfert galaxy NGC 5548 that has been carried 
out by the International AGN Watch consortium (Alloin et al. 1994). This program was initiated in late 1989 (Peterson et al. 1991) in support of a massive International Ultraviolet Explorer (IUE) monitoring program (Clavel et al. 1991). The ground-based program has continued uninterrupted since then, and it has also supported a second large multiwavelength project involving both Hubble Space Telescope, IUE (Korista et al. 1995), as well as the Extreme Ultraviolet Explorer (Marshall et al. 1997). Five years of ground-based data on optical continuum (at $5100 \AA$ ) and broad $\mathrm{H} \beta$ emission-line variations in NGC 5548 have already been published (Peterson et al. 1991, 1992, 1994; Korista et al. 1995). In this contribution, we present an additional $3 \mathrm{yr}$ of ground-based optical data on this source.

The principal aim of continuing this program is to search for changes in the BLR on a dynamical timescale that might be manifest in changes in the $\mathrm{H} \beta$ response time or in the emission-line profiles. This program also provides wellsampled continuum observations over an extended period, which may ultimately provide important clues about the origin of the continuum and its variability.

As is customary for the papers in this series, we will focus primarily on the data and the salient results of crosscorrelation analysis of the continuum and emission-line light curves. Further in-depth analysis will be left to other papers. In $\S 2$ we describe the observations, data reduction, and intercalibration procedures that we have used to construct a homogeneous database of optical continuum and $\mathrm{H} \beta$ emission-line fluxes. In $\S 3$, we describe the time-series analysis that we have undertaken to determine the timescale for response of $\mathrm{H} \beta$ to continuum variations. Our results are summarized in $\S 4$.

\section{OBSERVATIONS AND DATA ANALYSIS}

\subsection{Spectroscopic Observations}

Spectroscopic observations were obtained between UT 1993 November 17 (Julian Date = JD 2,449,309) and 1996 October 16 (JD 2,450,373), covering three separate observing seasons on NGC 5548. Throughout this paper we will refer to the interval 1993 November to 1994 October (JD $2,449,309$ to JD 2,449,636) as year 6, 1994 November to 1995 October (JD 2,449,679 to JD 2,450,008) as year 7, and 1995 November to 1996 October (JD 2,450,044 to JD 2,450, 373 ) as year 8 . During this $3 \mathrm{yr}$ period, a total of 309 spectra covering at least the $\mathrm{H} \beta$ region of the spectrum were obtained with CCD spectrographs on a wide variety of telescopes, as summarized in Table 1. Column (1) gives a code for each data set; these are the same codes that have been used throughout the NGC 5548 monitoring project. ${ }^{19}$

The spectroscopic images were processed by individual observers in standard fashion for CCD frames, including bias subtraction, flat-field correction, wavelength calibration, and flux calibration based on standard-star observations. However, the usual technique of flux calibration by comparison with standard stars is far too poor for AGN variability studies, since even under nominally photometric conditions, AGN spectrophotometry is rarely more accurate than $\sim 10 \%$. We therefore rely on standard-star calibration only for relative calibration, i.e., relative flux as a function of wavelength. Absolute calibration is based on the prominent narrow [O III] $\lambda 5007$ emission line. The narrow emission lines arise in a lower density region that is quite compact but still significantly larger than the BLR (Kraemer et al. 1998; Sergeev et al. 1997). The larger spatial extent and long recombination time mean that $[\mathrm{O}$ III $] \lambda 5007$ flux variations on the timescales discussed here will be undetectable. We therefore assume that the [O III] $\lambda 5007$ line remains constant in flux and can be used as an internal flux calibrator. All spectra are scaled to a constant flux of $F\left([\mathrm{O}\right.$ III $\lambda 5007)=5.58 \times 10^{-13} \mathrm{ergs} \mathrm{s}^{-1} \mathrm{~cm}^{-2}$. This absolute flux was determined from spectra made under photometric conditions during the first year of this program (Peterson et al. 1991). We have also measured the [O III] $\lambda 5007$ flux for the new spectra that were obtained through large spectrograph entrance apertures under photometric conditions, and these results are given in Table 2 . This is a conservative list, in that have we included only data where the observer recorded that the observing conditions appeared to be of photometric quality. These measurements suggest that the calibration that we have used for all $8 \mathrm{yr}$ might be too high by no more than a few percent, but there is no real evidence for time variability of the $[\mathrm{O}$ III $] \lambda 5007$ flux. We note, however, that some evidence for lowamplitude variability of [O III $] \lambda 5007$ on timescales of single observing seasons ( $\sim 200$ days) has been claimed (Sergeev et al. 1997), but this has little if any effect on the results reported here.

${ }^{19}$ The light curves and complete logs of observation, as have been published in our previous papers on NGC 5548, are available in tabular form at URL http://www.astronomy.ohio-state.edu/ agnwatch/. All publicly available International AGN Watch data can be accessed at this site, which also includes complete references to published AGN Watch papers.

TABLE 1

SOURCES OF SPECTROSCOPIC OBSERVATIONS

\begin{tabular}{|c|c|c|}
\hline $\begin{array}{l}\text { Data Set } \\
\text { (1) }\end{array}$ & $\begin{array}{l}\text { Telescope and Instrument } \\
\text { (2) }\end{array}$ & $\begin{array}{c}\text { Number of Spectra } \\
\text { (3) }\end{array}$ \\
\hline ...... & $1.8 \mathrm{~m}$ Perkins telescope + Ohio State CCD spectrograph & 95 \\
\hline $\mathrm{B} \ldots \ldots \ldots$ & $1.0 \mathrm{~m}$ Wise Observatory telescope + CCD spectrograph & 4 \\
\hline $\mathrm{D} \ldots \ldots \ldots$ & $5.0 \mathrm{~m}$ Hale telescope + double spectrograph & 2 \\
\hline $\mathrm{F} \ldots \ldots \ldots$ & $1.5 \mathrm{~m}$ Tillinghast reflector + FAST spectrograph & 89 \\
\hline H........ & $3.0 \mathrm{~m}$ Lick telescope + Kast spectrograph & 30 \\
\hline $\mathrm{J} \ldots \ldots \ldots$ & $2.1 \mathrm{~m}$ McDonald + Cassegrain grating spectrograph & 2 \\
\hline $\mathrm{L} \ldots \ldots .$. & $6 \mathrm{~m}$ Special Astrophysical Observatory telescope + CCD spectrographs & 2 \\
\hline M ....... & 3.5 and $2.2 \mathrm{~m}$ Calar Alto telescopes + CCD spectrograph & 2 \\
\hline $\mathrm{R} \ldots \ldots .$. & $1.5 \mathrm{~m}$ Loiano telescope + CCD spectrograph & 2 \\
\hline $\mathrm{W} \ldots \ldots$ & $2.6 \mathrm{~m}$ Shajn telescope + CCD spectrograph & 76 \\
\hline$Y \ldots \ldots .$. & $2.2 \mathrm{~m}$ Beijing Astronomical Observatory + CCD spectrograph & 4 \\
\hline $\mathrm{Z} \ldots \ldots \ldots$ & $3.6 \mathrm{~m}$ ESO telescope + CCD spectrograph & 1 \\
\hline
\end{tabular}


TABLE 2

Absolute Calibration Check

\begin{tabular}{|c|c|c|}
\hline $\begin{array}{c}F([\mathrm{O} \mathrm{III}] \lambda 5007) \\
\left(10^{-13} \mathrm{ergs} \mathrm{s}^{-1} \mathrm{~cm}^{-2}\right)\end{array}$ & File Name & UT Date \\
\hline 5.02 . & n59326a & 1993 Dec 4 \\
\hline $5.09 \ldots$ & n59332a & 1993 Dec 10 \\
\hline $5.04 \ldots$. & n59447h & 1994 Apr 4 \\
\hline $4.66 \ldots \ldots$ & $\mathrm{n} 59457 \mathrm{a}$ & 1994 Apr 15 \\
\hline $5.11 \ldots$ & n59464a & 1994 Apr 22 \\
\hline 5.22 . & $\mathrm{n} 59506 \mathrm{~h}$ & 1994 Jun 3 \\
\hline $5.30 \ldots$ & $\mathrm{n} 59513 \mathrm{a}$ & 1994 Jun 10 \\
\hline $5.86 \ldots$ & $\mathrm{n} 59519 \mathrm{~h}$ & 1994 Jun 13 \\
\hline $5.88 \ldots$ & $\mathrm{n} 59548 \mathrm{~h}$ & 1994 Jul 15 \\
\hline $6.37 \ldots$. & $\mathrm{n} 59568 \mathrm{~h}$ & 1994 Aug 4 \\
\hline $5.43 \ldots \ldots \ldots \ldots \ldots \ldots$ & n59861h & 1995 May 24 \\
\hline $5.49 \ldots \ldots \ldots \ldots \ldots \ldots$ & n59903a & 1995 Jul 5 \\
\hline $5.50 \ldots \ldots \ldots \ldots \ldots \ldots$ & $\mathrm{n} 59905 \mathrm{~h}$ & $1995 \mathrm{Jul} 7$ \\
\hline $5.22 \ldots \ldots \ldots \ldots \ldots \ldots$ & n59923a & $1995 \mathrm{Jul} 25$ \\
\hline $5.29 \ldots \ldots \ldots \ldots \ldots \ldots \ldots$ & n59958a & 1995 Aug 29 \\
\hline $5.75 \ldots \ldots \ldots \ldots \ldots \ldots$ & $\mathrm{n} 50060 \mathrm{a}$ & 1995 Dec 9 \\
\hline $5.39 \pm 0.42 \ldots \ldots \ldots \ldots$. & \multicolumn{2}{|c|}{ Mean value from years $6-8$} \\
\hline $5.58 \pm 0.27 .$. & \multicolumn{2}{|c|}{ Adopted absolute flux } \\
\hline
\end{tabular}

Once a standard [O III] $\lambda 5007$ flux has been adopted, all of the spectra are adjusted in flux to have this value. We have done this by employing the spectral scaling software described by van Groningen \& Wanders (1992). We adopt a high-quality spectrum that has been scaled by a multiplicative constant to the adopted [O III] $\lambda 5007$ flux as a "reference spectrum," and all other spectra are scaled relative to it in a least-squares fashion that minimizes the [O III] residuals in the difference spectrum produced by subtracting the reference spectrum from each program spectrum. This program also corrects for small zero-point wavelengthcalibration errors between the individual spectra and takes resolution differences into account.

At this point, measurements of each of the spectra are made. The continuum flux at $\sim 5100 \AA$ (in the rest frame of NGC $5548, z=0.0167$ ) is determined by averaging the flux in the 5185-5195 $\AA$ bandpass (in the observed frame). The $\mathrm{H} \beta$ emission-line flux is measured by assuming a straight underlying continuum between $\sim 4790$ and $\sim 5170 \AA$ and integrating the flux above this continuum between 4795 and $5018 \AA$ (all wavelengths in the observed frame). The longwavelength cutoff of this integration band misses some of the $\mathrm{H} \beta$ flux underneath [O III] $\lambda 4959$, but this avoids the need to estimate the $\mathrm{Fe}$ II contribution to this feature and still gives a good representation of the $\mathrm{H} \beta$ variability. We also note that no attempt has been made to correct for contamination of the line measurement by the narrow-line component of $\mathrm{H} \beta$, which is of course expected to be constant. Recent estimates of the strength of narrow-line $\mathrm{H} \beta$ range between $0.12 F([\mathrm{O}$ III $]$ 25007) (Kraemer et al. 1998) and $0.151 F([\mathrm{O} \mathrm{III}] 25007)$ (Wanders \& Peterson 1996), in any case typically only $\sim 10 \%$ of the measured $\mathrm{H} \beta$ flux.

Even after scaling all of the spectra to a common value of the [O III] $\lambda 5007$ flux, there are systematic differences between the light curves produced from data obtained at different telescopes. As in our previous papers, we correct for the small offsets between the light curves from different sources in a simple, but effective, fashion. We attribute these small relative offsets to aperture effects (Peterson et al.
1995), although the procedure we use also corrects for other unidentified systematic differences between data sets. We define a point-source correction factor $\varphi$ by the equation

$$
F(\mathrm{H} \beta)_{\text {true }}=\varphi F(\mathrm{H} \beta)_{\text {observed }} .
$$

This factor accounts for the fact that different apertures result in different amounts of light loss for the point-spread function (which describes the surface-brightness distribution of both the broad lines and the AGN continuum source) and the partially extended narrow-line region. We note, of course, that this correction factor is in fact a function of seeing (Peterson et al. 1995). We do not attempt to correct for seeing effects, and this is probably our largest single source of uncertainty.

After correcting for aperture effects on the point-spread function to narrow-line ratio, another correction needs to be applied to adjust for the different amounts of starlight admitted by different apertures. An extended source correction $G$ is thus defined as

$$
F_{\lambda}(5100 \AA)_{\text {true }}=\varphi F_{\lambda}(5100 \AA)_{\text {observed }}-G .
$$

Intercalibration of the various data sets is then accomplished by comparing pairs of nearly simultaneous observations from different data sets to determine for each data set the values of the constants $\varphi$ and $G$, which are needed to adjust the emission-line and continuum fluxes to a common scale. Furthermore, the formal uncertainties in $\varphi$ and $G$ reflect the uncertainties in the individual data sets, so we can determine the nominal uncertainties for each data set if we assume that the errors add in quadrature. In practice, the interval which we define as "nearly simultaneous" is typically 1 or 2 days, which means that any real variability that occurs on timescales this short tends to be somewhat suppressed by the process that allows us to merge the different data sets.

As in our previous work, the data are adjusted relative to data set "A," because these data are fairly extensive, overlap well with most of the other data sets, and were obtained through a reasonably large aperture $\left(5^{\prime \prime} 0 \times 77^{\prime \prime} .5\right)$. Fractional uncertainties of $\sigma_{\text {cont }} / F_{\lambda}(5100 \AA) \approx 0.020$ and $\sigma_{\text {line }} / F(\mathrm{H} \beta) \approx$ 0.020 for the continuum and $\mathrm{H} \beta$ line, respectively, are adopted for the similar, large-aperture, high-quality data sets " $A$ " and " $H$," based on the differences between closely spaced observations within these sets (see also Peterson et al. 1998a). For the other data sets, it was possible to estimate the mean uncertainties in the measurements by comparing them to measurements from other sets for which the uncertainties are known and by assuming that the uncertainties for each set add in quadrature.

The intercalibration constants we use for each data set are given in Table 3, and these constants are used with equations (3) and (4) to adjust the spectral measurements. We note that it was not possible to find a single set of correction factors for the data in set " $F$," probably on account of modifications to the instrument made during this period (Fabricant et al. 1998). We have thus determined separate intercalibration constants for each of the $3 \mathrm{yr}$.

The final continuum $\left[F_{\lambda}(5100 \AA)\right]$ and $\mathrm{H} \beta$ emission-line fluxes are given in Table 4. Simultaneous (to within 0.1 day) measurements were averaged, weighted by the reciprocal of their variances. We can perform a final check of our uncertainty estimates by examining the ratios of all pairs of observations in Table 4 that are separated by 1 day or less. There are 160 independent pairs of measurements within 1 
TABLE 3

Flux Scale Factors for Optical Spectra

\begin{tabular}{|c|c|c|}
\hline $\begin{array}{l}\text { Data Set } \\
\text { (1) }\end{array}$ & $\begin{array}{l}\text { Point-Source } \\
\text { Scale Factor } \\
\qquad(\varphi) \\
(2)\end{array}$ & $\begin{array}{c}\text { Extended Source Correction } \\
G\left(10^{-15} \mathrm{ergs} \mathrm{s}^{-1} \mathrm{~cm}^{-2} \AA^{-1}\right) \\
\text { (3) }\end{array}$ \\
\hline $\mathrm{A} \ldots \ldots \ldots \ldots \ldots$ & 1.000 & 0.000 \\
\hline B ............ & $0.998 \pm 0.013$ & $-0.349 \pm 0.342$ \\
\hline $\mathrm{D} \ldots \ldots \ldots \ldots \ldots$ & $0.983 \pm 0.020$ & $-0.228 \pm 0.199$ \\
\hline$F($ year 6$) \ldots . .$. & $0.873 \pm 0.055$ & $-1.626 \pm 0.407$ \\
\hline$F($ year 7)...... & $1.028 \pm 0.041$ & $-0.067 \pm 0.419$ \\
\hline$F($ year 8$) \ldots . .$. & $0.965 \pm 0.035$ & $-1.344 \pm 0.373$ \\
\hline H.............. & $1.000 \pm 0.030$ & $0.000 \pm 0.267$ \\
\hline J ................ & $1.025 \pm 0.032$ & $0.046 \pm 0.471$ \\
\hline$L \ldots \ldots . .$. & $0.893 \pm 0.038$ & $-1.907 \pm 0.748$ \\
\hline M .............. & $0.759 \pm 0.015$ & $-1.381 \pm 0.126$ \\
\hline $\mathrm{R} \ldots \ldots \ldots \ldots \ldots$ & $0.863 \pm 0.025$ & $-1.900 \pm 1.065$ \\
\hline $\mathrm{W} \ldots$. & $0.940 \pm 0.040$ & $-1.149 \pm 0.388$ \\
\hline $\mathrm{Y} \ldots \ldots \ldots \ldots \ldots$ & $1.093 \pm 0.084$ & $-0.471 \pm 0.381$ \\
\hline $\mathrm{Z} \ldots \ldots \ldots \ldots$ & $1 . \overline{001}$ & $0 . \overline{16} 1$ \\
\hline
\end{tabular}

day. The dispersion about the mean (unity), divided by $2^{1 / 2}$, provides an estimate of the typical uncertainty in a single measurement. For the continuum, we find that the mean fractional error in a given measurement is 0.032 . The average fractional uncertainty, from the quoted estimates for these same 160 pairs of measurements, is 0.035 . Similarly, for the $\mathrm{H} \beta$ light curve, we find that the mean fractional error in a given measurement is 0.031 . The average fractional uncertainty from the quoted estimates for these same 160 pairs of measurements is 0.035 . These numbers imply that our error estimates are probably quite good. The mean fractional errors in this data set are somewhat superior to those quoted in our earlier papers, and this is probably due to the fact that, in contrast to the past, all of the data reported here were obtained with CCD detectors.

\subsection{Photometric Observations}

In addition to the spectroscopic observations, a limited amount of CCD photometric data also have been obtained.

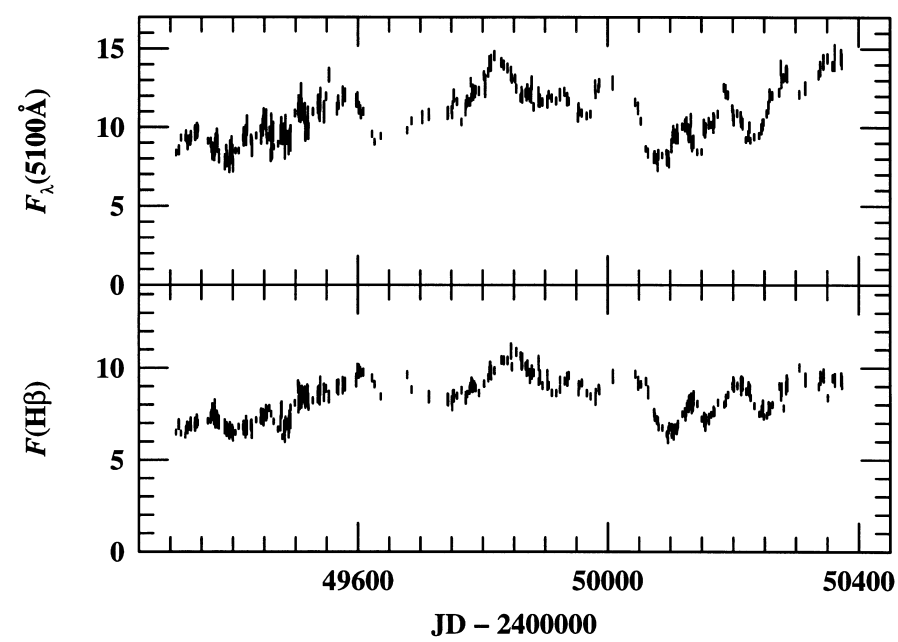

FIG. 1.-Optical continuum (upper panel) and $\mathrm{H} \beta$ emission-line light curves for NGC 5548 between 1993 November and 1996 October. These are based on 309 optical spectra and 14 photometric observations reported here. The continuum fluxes are in units of $10^{-15} \mathrm{ergs} \mathrm{s}^{-1} \mathrm{~cm}^{-2} \AA^{-1}$, and the line fluxes are in units of $10^{-13} \mathrm{ergs} \mathrm{s}^{-1} \mathrm{~cm}^{-2}$. The $\sim 20$ day time delay between continuum and emission-line variations is apparent.
TABLE 4

Optical ContinuUm and H $\beta$ Light CuRves

\begin{tabular}{|c|c|c|}
\hline $\begin{array}{l}\text { Julian Date } \\
(-2,400,000)\end{array}$ & $\begin{array}{c}F_{\lambda}(5100 \AA) \\
\left(10^{-15} \operatorname{ergs~s}^{-1} \mathrm{~cm}^{-2} \AA^{-1}\right)\end{array}$ & $\begin{array}{c}F(\mathrm{H} \beta) \\
\left(10^{-13} \mathrm{ergs} \mathrm{s}^{-1} \mathrm{~cm}^{-2}\right)\end{array}$ \\
\hline $49309.1 \ldots \ldots$ & $8.37 \pm 0.17$ & $6.51 \pm 0.13$ \\
\hline $49313.6 \ldots \ldots$ & $8.54 \pm 0.28$ & $6.94 \pm 0.26$ \\
\hline $49317.0 \ldots \ldots$ & $9.32 \pm 0.19$ & $6.45 \pm 0.13$ \\
\hline $49324.0 \ldots \ldots$ & $9.33 \pm 0.19$ & $6.34 \pm 0.13$ \\
\hline $49325.0 \ldots \ldots$ & $9.59 \pm 0.19$ & $6.69 \pm 0.13$ \\
\hline $49326.0 \ldots \ldots$ & $9.23 \pm 0.19$ & $6.73 \pm 0.14$ \\
\hline $49327.0 \ldots \ldots$ & $9.14 \pm 0.18$ & $6.94 \pm 0.14$ \\
\hline $49327.6 \ldots \ldots$ & $8.86 \pm 0.29$ & $6.68 \pm 0.25$ \\
\hline $49328.0 \ldots \ldots$ & $9.24 \pm 0.19$ & $6.74 \pm 0.14$ \\
\hline $49329.0 \ldots \ldots$ & $9.04 \pm 0.18$ & $6.86 \pm 0.14$ \\
\hline $49330.0 \ldots \ldots$ & $9.27 \pm 0.19$ & $6.86 \pm 0.14$ \\
\hline $49331.0 \ldots \ldots$ & $9.27 \pm 0.19$ & $6.78 \pm 0.14$ \\
\hline $49332.0 \ldots \ldots$ & $9.05 \pm 0.18$ & $6.99 \pm 0.14$ \\
\hline $49332.6 \ldots \ldots$ & $9.44 \pm 0.31$ & $7.02 \pm 0.27$ \\
\hline $49333.0 \ldots \ldots$ & $9.30 \pm 0.19$ & $6.74 \pm 0.14$ \\
\hline $49339.0 \ldots \ldots$ & $9.81 \pm 0.20$ & $6.91 \pm 0.14$ \\
\hline $49339.7 \ldots \ldots$ & $9.64 \pm 0.48$ & $6.93 \pm 0.35$ \\
\hline $49340.1 \ldots \ldots$ & $9.69 \pm 0.19$ & $7.15 \pm 0.14$ \\
\hline $49342.4 \ldots \ldots$ & $9.78 \pm 0.49$ & $7.10 \pm 0.35$ \\
\hline $49343.1 \ldots \ldots$ & $9.59 \pm 0.19$ & $7.03 \pm 0.14$ \\
\hline $49344.1 \ldots \ldots$ & $9.91 \pm 0.20$ & $7.03 \pm 0.14$ \\
\hline $49360.1 \ldots \ldots$ & $9.13 \pm 0.18$ & $7.12 \pm 0.14$ \\
\hline $49364.6 \ldots \ldots$ & $9.02 \pm 0.30$ & $7.29 \pm 0.28$ \\
\hline $49365.6 \ldots \ldots$ & $8.69 \pm 0.29$ & $7.43 \pm 0.28$ \\
\hline $49367.0 \ldots \ldots$ & $8.48 \pm 0.53$ & $7.64 \pm 0.43$ \\
\hline $49370.0 \ldots \ldots$ & $8.40 \pm 0.52$ & $7.33 \pm 0.41$ \\
\hline $49371.0 \ldots \ldots$ & $8.74 \pm 0.54$ & $7.84 \pm 0.44$ \\
\hline $49372.0 \ldots \ldots$ & $9.02 \pm 0.56$ & $7.15 \pm 0.40$ \\
\hline $49372.1 \ldots \ldots$ & $9.38 \pm 0.19$ & $7.20 \pm 0.14$ \\
\hline $49374.0 \ldots \ldots$ & $9.31 \pm 0.58$ & $7.26 \pm 0.41$ \\
\hline $49375.0 \ldots \ldots$ & $8.98 \pm 0.56$ & $7.15 \pm 0.40$ \\
\hline $49377.7 \ldots \ldots$ & $8.16 \pm 0.41$ & $7.05 \pm 0.35$ \\
\hline $49387.0 \ldots \ldots$ & $7.79 \pm 0.48$ & $6.81 \pm 0.38$ \\
\hline $49389.1 \ldots \ldots$ & $8.69 \pm 0.17$ & $6.83 \pm 0.14$ \\
\hline $49390.0 \ldots \ldots$ & $8.00 \pm 0.50$ & $6.67 \pm 0.37$ \\
\hline $49394.0 \ldots \ldots$ & $7.59 \pm 0.47$ & $6.53 \pm 0.37$ \\
\hline $49395.0 \ldots \ldots$ & $8.15 \pm 0.51$ & $6.68 \pm 0.37$ \\
\hline $49395.6 \ldots \ldots$ & $8.87 \pm 0.29$ & $6.53 \pm 0.25$ \\
\hline $49397.6 \ldots \ldots$ & $9.11 \pm 0.30$ & $6.61 \pm 0.25$ \\
\hline $49399.0 \ldots \ldots$ & $8.34 \pm 0.52$ & $6.53 \pm 0.37$ \\
\hline $49400.0 \ldots \ldots$ & $7.64 \pm 0.47$ & $6.41 \pm 0.36$ \\
\hline $49403.8 \ldots \ldots$ & $8.51 \pm 0.17$ & $6.49 \pm 0.13$ \\
\hline $49409.0 \ldots \ldots$ & $8.51 \pm 0.17$ & $6.81 \pm 0.14$ \\
\hline $49415.9 \ldots \ldots$ & $9.32 \pm 0.19$ & $6.78 \pm 0.14$ \\
\hline $49416.9 \ldots \ldots$ & $9.40 \pm 0.58$ & $6.75 \pm 0.38$ \\
\hline $49420.0 \ldots \ldots$ & $9.53 \pm 0.59$ & $6.58 \pm 0.37$ \\
\hline $49420.9 \ldots \ldots$ & $9.45 \pm 0.19$ & $7.05 \pm 0.14$ \\
\hline $49421.0 \ldots \ldots$ & $9.44 \pm 0.59$ & $6.99 \pm 0.39$ \\
\hline $49422.0 \ldots \ldots$ & $10.12 \pm 0.63$ & $6.76 \pm 0.38$ \\
\hline $49428.6 \ldots \ldots$ & $9.22 \pm 0.30$ & $6.88 \pm 0.26$ \\
\hline $49429.1 \ldots \ldots$ & $9.19 \pm 0.18$ & $7.03 \pm 0.14$ \\
\hline $49429.8 \ldots \ldots$ & $9.24 \pm 0.19$ & $7.04 \pm 0.14$ \\
\hline $49429.9 \ldots \ldots$ & $8.68 \pm 0.54$ & $6.55 \pm 0.37$ \\
\hline $49436.9 \ldots \ldots$ & $9.46 \pm 0.19$ & $7.17 \pm 0.14$ \\
\hline $49443.9 \ldots \ldots$ & $9.90 \pm 0.19$ & $7.16 \pm 0.13$ \\
\hline $49444.8 \ldots \ldots$ & $9.54 \pm 0.59$ & $7.37 \pm 0.41$ \\
\hline $49447.0 \ldots \ldots$ & $10.32 \pm 0.21$ & $7.60 \pm 0.15$ \\
\hline $49447.9 \ldots \ldots$ & $10.10 \pm 0.63$ & $7.35 \pm 0.41$ \\
\hline $49448.9 \ldots \ldots$ & $10.56 \pm 0.65$ & $7.28 \pm 0.41$ \\
\hline $49452.8 \ldots \ldots$ & $10.49 \pm 0.65$ & $7.55 \pm 0.42$ \\
\hline $49453.3 \ldots \ldots$ & $9.66 \pm 0.32$ & $7.43 \pm 0.28$ \\
\hline $49454.4 \ldots \ldots$ & $9.27 \pm 0.31$ & $7.57 \pm 0.29$ \\
\hline $49457.9 \ldots \ldots$ & $9.41 \pm 0.19$ & $7.82 \pm 0.16$ \\
\hline $49461.0 \ldots \ldots$ & $8.72 \pm 0.17$ & $7.50 \pm 0.15$ \\
\hline $49464.8 \ldots \ldots$ & $8.74 \pm 0.17$ & $7.09 \pm 0.14$ \\
\hline
\end{tabular}


TABLE 4-Continued

\begin{tabular}{|c|c|c|}
\hline $\begin{array}{l}\text { Julian Date } \\
(-2,400,000)\end{array}$ & $\begin{array}{c}F_{\lambda}(5100 \AA) \\
\left(10^{-15} \operatorname{ergs~s}^{-1} \mathrm{~cm}^{-2} \AA^{-1}\right)\end{array}$ & $\begin{array}{c}F(\mathrm{H} \beta) \\
\left(10^{-13} \mathrm{ergs} \mathrm{s}^{-1} \mathrm{~cm}^{-2}\right)\end{array}$ \\
\hline $49471.8 \ldots \ldots$ & $8.94 \pm 0.18$ & $6.67 \pm 0.13$ \\
\hline $49475.8 \ldots \ldots$ & $9.54 \pm 0.59$ & $6.98 \pm 0.39$ \\
\hline $49476.9 \ldots \ldots$ & $10.01 \pm 0.62$ & $7.68 \pm 0.43$ \\
\hline $49477.8 \ldots \ldots$ & $9.57 \pm 0.59$ & $7.74 \pm 0.43$ \\
\hline $49478.8 \ldots \ldots$ & $9.09 \pm 0.18$ & $6.26 \pm 0.12$ \\
\hline $49481.8 \ldots \ldots$ & $9.64 \pm 0.60$ & $6.76 \pm 0.38$ \\
\hline $49482.8 \ldots \ldots$ & $8.51 \pm 0.53$ & $6.32 \pm 0.35$ \\
\hline $49483.7 \ldots \ldots$ & $10.14 \pm 0.63$ & $6.97 \pm 0.39$ \\
\hline $49485.8 \ldots \ldots$ & $9.57 \pm 0.19$ & $6.88 \pm 0.14$ \\
\hline $49486.4 \ldots \ldots$ & $9.25 \pm 0.31$ & $6.93 \pm 0.26$ \\
\hline $49487.4 \ldots \ldots$ & $9.28 \pm 0.31$ & $6.97 \pm 0.26$ \\
\hline $49488.8 \ldots \ldots$ & $8.81 \pm 0.55$ & $6.58 \pm 0.37$ \\
\hline $49489.4 \ldots \ldots$ & $9.12 \pm 0.30$ & $7.13 \pm 0.27$ \\
\hline $49489.8 \ldots \ldots$ & $9.22 \pm 0.57$ & $6.86 \pm 0.38$ \\
\hline $49490.1 \ldots \ldots$ & $9.17 \pm 0.30$ & $7.39 \pm 0.28$ \\
\hline $49490.4 \ldots \ldots$ & $9.21 \pm 0.30$ & $6.99 \pm 0.27$ \\
\hline $49491.1 \ldots \ldots$ & $9.61 \pm 0.32$ & $7.17 \pm 0.27$ \\
\hline $49491.4 \ldots \ldots$ & $9.33 \pm 0.31$ & $7.15 \pm 0.27$ \\
\hline $49491.6 \ldots \ldots$ & $9.05 \pm 0.56$ & $7.12 \pm 0.40$ \\
\hline $49491.8 \ldots \ldots$ & $9.91 \pm 0.20$ & $7.83 \pm 0.16$ \\
\hline $49498.8 \ldots \ldots$ & $10.90 \pm 0.22$ & $8.09 \pm 0.16$ \\
\hline $49504.1 \ldots \ldots$ & $11.16 \pm 0.37$ & $8.98 \pm 0.34$ \\
\hline $49504.7 \ldots \ldots$ & $11.33 \pm 0.70$ & $8.02 \pm 0.45$ \\
\hline $49505.6 \ldots \ldots$ & $11.07 \pm 0.69$ & $8.69 \pm 0.49$ \\
\hline $49506.7 \ldots \ldots$ & $11.17 \pm 0.21$ & $7.99 \pm 0.15$ \\
\hline $49506.9 \ldots \ldots$ & $11.47 \pm 0.23$ & $7.90 \pm 0.16$ \\
\hline $49507.7 \ldots \ldots$ & $11.02 \pm 0.68$ & $8.37 \pm 0.47$ \\
\hline $49508.7 \ldots \ldots$ & $12.06 \pm 0.75$ & $8.51 \pm 0.48$ \\
\hline $49509.7 \ldots \ldots$ & $11.15 \pm 0.69$ & $8.30 \pm 0.47$ \\
\hline $49510.4 \ldots \ldots$ & $11.10 \pm 0.37$ & $8.70 \pm 0.33$ \\
\hline $49513.7 \ldots \ldots$ & $10.50 \pm 0.20$ & $8.32 \pm 0.16$ \\
\hline $49514.7 \ldots \ldots$ & $10.88 \pm 0.67$ & $8.50 \pm 0.48$ \\
\hline $49515.7 \ldots \ldots$ & $9.73 \pm 0.60$ & $8.29 \pm 0.46$ \\
\hline $49518.7 \ldots \ldots$ & $10.03 \pm 0.62$ & $8.61 \pm 0.48$ \\
\hline $49519.4 \ldots \ldots$ & $9.84 \pm 0.32$ & $8.32 \pm 0.32$ \\
\hline $49519.5 \ldots \ldots$ & $10.18 \pm 0.20$ & $8.56 \pm 0.17$ \\
\hline $49519.7 \ldots \ldots$ & $10.65 \pm 0.66$ & $8.57 \pm 0.48$ \\
\hline $49520.4 \ldots \ldots$ & $9.54 \pm 0.31$ & $8.29 \pm 0.31$ \\
\hline $49520.7 \ldots \ldots$ & $10.09 \pm 0.19$ & $7.87 \pm 0.15$ \\
\hline $49527.7 \ldots \ldots$ & $11.00 \pm 0.22$ & $8.23 \pm 0.17$ \\
\hline $49535.4 \ldots \ldots$ & $11.28 \pm 0.37$ & $8.44 \pm 0.32$ \\
\hline $49536.3 \ldots \ldots$ & $11.69 \pm 0.39$ & $8.65 \pm 0.33$ \\
\hline $49537.7 \ldots \ldots$ & $11.25 \pm 0.70$ & $8.55 \pm 0.48$ \\
\hline $49538.7 \ldots \ldots$ & $11.08 \pm 0.69$ & $8.47 \pm 0.47$ \\
\hline $49539.7 \ldots \ldots$ & $11.77 \pm 0.73$ & $9.02 \pm 0.50$ \\
\hline $49545.6 \ldots \ldots$ & $10.97 \pm 0.68$ & $8.67 \pm 0.48$ \\
\hline $49548.8 \ldots \ldots$ & $11.97 \pm 0.24$ & $8.88 \pm 0.18$ \\
\hline $49553.4 \ldots \ldots$ & $13.35 \pm 0.44$ & $8.43 \pm 0.32$ \\
\hline $49566.3 \ldots \ldots$ & $11.18 \pm 0.37$ & $8.99 \pm 0.34$ \\
\hline $49568.4 \ldots \ldots$ & $11.64 \pm 0.38$ & $8.90 \pm 0.34$ \\
\hline $49568.8 \ldots \ldots$ & $11.39 \pm 0.23$ & $9.19 \pm 0.18$ \\
\hline $49575.5 \ldots \ldots$ & $11.99 \pm 0.60$ & $9.05 \pm 0.45$ \\
\hline $49579.3 \ldots \ldots$ & $12.06 \pm 0.40$ & $9.11 \pm 0.35$ \\
\hline $49597.3 \ldots \ldots$ & $11.72 \pm 0.39$ & $9.33 \pm 0.35$ \\
\hline $49597.7 \ldots \ldots$ & $11.45 \pm 0.16$ & $9.55 \pm 0.14$ \\
\hline $49599.3 \ldots \ldots$ & $11.83 \pm 0.39$ & $9.85 \pm 0.37$ \\
\hline $49601.3 \ldots \ldots$ & $11.24 \pm 0.37$ & $9.82 \pm 0.37$ \\
\hline $49603.7 \ldots \ldots$ & $11.18 \pm 0.22$ & $9.84 \pm 0.20$ \\
\hline $49604.7 \ldots \ldots$ & $10.80 \pm 0.22$ & $9.72 \pm 0.19$ \\
\hline $49608.7 \ldots \ldots$ & $11.01 \pm 0.22$ & $9.76 \pm 0.19$ \\
\hline $49622.6 \ldots \ldots$ & $9.57 \pm 0.19$ & $9.45 \pm 0.19$ \\
\hline $49626.6 \ldots \ldots$ & $9.06 \pm 0.18$ & $9.11 \pm 0.18$ \\
\hline $49636.6 \ldots \ldots$ & $9.44 \pm 0.19$ & $8.44 \pm 0.17$ \\
\hline $49679.0 \ldots \ldots$ & $9.81 \pm 0.20$ & $9.63 \pm 0.19$ \\
\hline $49686.0 \ldots \ldots$ & $10.41 \pm 0.21$ & $8.82 \pm 0.18$ \\
\hline
\end{tabular}

TABLE 4-Continued

\begin{tabular}{|c|c|c|}
\hline $\begin{array}{l}\text { Julian Date } \\
(-2,400,000)\end{array}$ & $\begin{array}{c}F_{\lambda}(5100 \AA) \\
\left(10^{-15} \operatorname{ergs~s}^{-1} \mathrm{~cm}^{-2} \AA^{-1}\right)\end{array}$ & $\begin{array}{c}F(\mathrm{H} \beta) \\
\left(10^{-13} \mathrm{ergs} \mathrm{s}^{-1} \mathrm{~cm}^{-2}\right)\end{array}$ \\
\hline $49713.6 \ldots \ldots$ & $10.82 \pm 0.36$ & $8.43 \pm 0.32$ \\
\hline $49743.6 \ldots \ldots$ & $10.89 \pm 0.36$ & $8.29 \pm 0.31$ \\
\hline $49744.5 \ldots \ldots$ & $10.95 \pm 0.36$ & $8.27 \pm 0.31$ \\
\hline $49750.1 \ldots \ldots$ & $11.12 \pm 0.22$ & $8.24 \pm 0.21$ \\
\hline $49751.0 \ldots \ldots$ & $10.77 \pm 0.22$ & $7.89 \pm 0.20$ \\
\hline $49752.0 \ldots \ldots$ & $11.43 \pm 0.23$ & $8.61 \pm 0.17$ \\
\hline $49753.6 \ldots \ldots$ & $12.02 \pm 0.40$ & $8.48 \pm 0.32$ \\
\hline $49758.9 \ldots \ldots$ & $11.65 \pm 0.23$ & $8.48 \pm 0.17$ \\
\hline $49765.9 \ldots \ldots$ & $10.34 \pm 0.21$ & $8.78 \pm 0.18$ \\
\hline $49772.5 \ldots \ldots$ & $11.14 \pm 0.37$ & $8.37 \pm 0.32$ \\
\hline $49772.9 \ldots \ldots$ & $11.39 \pm 0.23$ & $8.21 \pm 0.16$ \\
\hline $49773.1 \ldots \ldots$ & $11.50 \pm 0.23$ & $8.40 \pm 0.17$ \\
\hline $49775.0 \ldots \ldots$ & $11.68 \pm 0.35$ & $8.58 \pm 0.17$ \\
\hline $49779.0 \ldots \ldots$ & $11.61 \pm 0.23$ & $8.81 \pm 0.22$ \\
\hline $49780.0 \ldots \ldots$ & $11.63 \pm 0.23$ & $8.97 \pm 0.22$ \\
\hline $49781.0 \ldots \ldots$ & $12.88 \pm 0.26$ & $8.94 \pm 0.22$ \\
\hline $49782.0 \ldots \ldots$ & $11.92 \pm 0.24$ & $9.25 \pm 0.23$ \\
\hline $49783.5 \ldots \ldots$ & $12.27 \pm 0.41$ & $9.02 \pm 0.34$ \\
\hline $49784.0 \ldots \ldots$ & $12.47 \pm 0.25$ & $9.08 \pm 0.23$ \\
\hline $49784.5 \ldots \ldots$ & $12.16 \pm 0.24$ & $8.99 \pm 0.18$ \\
\hline $49784.9 \ldots \ldots$ & $12.00 \pm 0.24$ & $8.89 \pm 0.18$ \\
\hline $49786.6 \ldots \ldots$ & $12.40 \pm 0.25$ & $9.09 \pm 0.18$ \\
\hline $49787.6 \ldots \ldots$ & $12.17 \pm 0.24$ & $8.97 \pm 0.18$ \\
\hline $49788.5 \ldots \ldots$ & $12.39 \pm 0.25$ & $8.90 \pm 0.18$ \\
\hline $49794.0 \ldots \ldots$ & $12.32 \pm 0.25$ & $8.63 \pm 0.17$ \\
\hline $49802.0 \ldots \ldots$ & $13.31 \pm 0.27$ & $9.14 \pm 0.18$ \\
\hline $49808.9 \ldots \ldots$ & $13.50 \pm 0.27$ & $9.46 \pm 0.19$ \\
\hline $49810.8 \ldots \ldots$ & $14.25 \pm 0.28$ & $9.82 \pm 0.25$ \\
\hline $49810.9 \ldots \ldots$ & $14.00 \pm 0.42$ & $9.82 \pm 0.20$ \\
\hline $49811.8 \ldots \ldots$ & $14.17 \pm 0.28$ & $10.10 \pm 0.25$ \\
\hline $49813.0 \ldots \ldots$ & $13.88 \pm 0.28$ & $9.72 \pm 0.24$ \\
\hline $49813.6 \ldots \ldots$ & $14.14 \pm 0.47$ & $9.74 \pm 0.37$ \\
\hline $49818.8 \ldots \ldots$ & $14.56 \pm 0.29$ & $9.85 \pm 0.20$ \\
\hline $49830.0 \ldots \ldots$ & $14.13 \pm 0.28$ & $10.43 \pm 0.21$ \\
\hline $49833.8 \ldots \ldots$ & $13.96 \pm 0.28$ & $10.41 \pm 0.21$ \\
\hline $49839.8 \ldots \ldots$ & $13.77 \pm 0.28$ & $10.40 \pm 0.21$ \\
\hline $49845.4 \ldots \ldots$ & $13.42 \pm 0.44$ & $10.92 \pm 0.41$ \\
\hline $49846.8 \ldots \ldots$ & $13.11 \pm 0.26$ & $10.07 \pm 0.20$ \\
\hline $49853.8 \ldots \ldots$ & $12.47 \pm 0.25$ & $10.87 \pm 0.22$ \\
\hline $49860.8 \ldots \ldots$ & $11.88 \pm 0.24$ & $10.64 \pm 0.21$ \\
\hline $49861.9 \ldots \ldots$ & $11.96 \pm 0.24$ & $10.16 \pm 0.20$ \\
\hline $49862.3 \ldots \ldots$ & $12.17 \pm 0.40$ & $10.29 \pm 0.39$ \\
\hline $49863.3 \ldots \ldots$ & $11.97 \pm 0.40$ & $10.39 \pm 0.40$ \\
\hline $49868.8 \ldots \ldots$ & $12.19 \pm 0.24$ & $10.09 \pm 0.20$ \\
\hline $49870.4 \ldots \ldots$ & $12.11 \pm 0.40$ & $9.94 \pm 0.38$ \\
\hline $49871.4 \ldots \ldots$ & $12.34 \pm 0.41$ & $10.03 \pm 0.38$ \\
\hline $49871.7 \ldots \ldots$ & $12.28 \pm 0.25$ & $10.03 \pm 0.25$ \\
\hline $49874.7 \ldots \ldots$ & $12.03 \pm 0.24$ & $9.76 \pm 0.19$ \\
\hline $49875.4 \ldots \ldots$ & $12.06 \pm 0.40$ & $9.54 \pm 0.36$ \\
\hline $49878.4 \ldots \ldots$ & $12.82 \pm 0.42$ & $9.77 \pm 0.37$ \\
\hline $49881.7 \ldots \ldots$ & $11.31 \pm 0.23$ & $9.73 \pm 0.19$ \\
\hline $49889.4 \ldots \ldots$ & $12.15 \pm 0.40$ & $10.27 \pm 0.39$ \\
\hline $49889.7 \ldots \ldots$ & $11.56 \pm 0.23$ & $9.26 \pm 0.19$ \\
\hline $49891.4 \ldots \ldots$ & $11.71 \pm 0.39$ & $9.51 \pm 0.36$ \\
\hline $49895.7 \ldots \ldots$ & $11.62 \pm 0.23$ & $9.04 \pm 0.18$ \\
\hline $49903.3 \ldots \ldots$ & $11.64 \pm 0.38$ & $9.52 \pm 0.36$ \\
\hline $49903.7 \ldots \ldots$ & $11.48 \pm 0.23$ & $8.98 \pm 0.18$ \\
\hline $49905.8 \ldots \ldots$ & $12.08 \pm 0.24$ & $9.05 \pm 0.18$ \\
\hline $49910.7 \ldots \ldots$ & $11.86 \pm 0.24$ & $8.64 \pm 0.17$ \\
\hline $49917.7 \ldots \ldots$ & $11.69 \pm 0.23$ & $8.62 \pm 0.17$ \\
\hline $49923.7 \ldots \ldots$ & $12.21 \pm 0.24$ & $8.83 \pm 0.18$ \\
\hline $49923.8 \ldots \ldots$ & $11.95 \pm 0.24$ & $9.33 \pm 0.19$ \\
\hline $49930.8 \ldots \ldots$ & $12.27 \pm 0.25$ & $9.28 \pm 0.19$ \\
\hline $49935.3 \ldots \ldots$ & $11.80 \pm 0.39$ & $9.38 \pm 0.36$ \\
\hline $49937.7 \ldots \ldots$ & $11.67 \pm 0.23$ & $9.58 \pm 0.19$ \\
\hline
\end{tabular}


TABLE 4-Continued

\begin{tabular}{|c|c|c|}
\hline $\begin{array}{l}\text { Julian Date } \\
(-2,400,000)\end{array}$ & $\begin{array}{c}F_{\lambda}(5100 \AA) \\
\left(10^{-15} \operatorname{ergs~s}^{-1} \mathrm{~cm}^{-2} \AA^{-1}\right)\end{array}$ & $\begin{array}{c}F(\mathrm{H} \beta) \\
\left(10^{-13} \mathrm{ergs} \mathrm{s}^{-1} \mathrm{~cm}^{-2}\right)\end{array}$ \\
\hline $49953.3 \ldots \ldots$ & $11.07 \pm 0.37$ & $8.85 \pm 0.34$ \\
\hline $49953.7 \ldots \ldots$ & $11.31 \pm 0.23$ & $9.10 \pm 0.18$ \\
\hline $49954.7 \ldots \ldots$ & $11.01 \pm 0.22$ & $9.04 \pm 0.18$ \\
\hline $49958.7 \ldots \ldots$ & $10.91 \pm 0.22$ & $9.18 \pm 0.18$ \\
\hline $49966.6 \ldots \ldots$ & $10.73 \pm 0.22$ & $8.63 \pm 0.17$ \\
\hline $49972.6 \ldots \ldots$ & $10.85 \pm 0.22$ & $8.46 \pm 0.17$ \\
\hline $49980.3 \ldots \ldots$ & $12.59 \pm 0.41$ & $8.31 \pm 0.32$ \\
\hline $49980.6 \ldots \ldots$ & $12.12 \pm 0.24$ & $8.69 \pm 0.17$ \\
\hline $49985.6 \ldots \ldots$ & $12.51 \pm 0.25$ & $8.90 \pm 0.18$ \\
\hline $49986.6 \ldots \ldots$ & $12.81 \pm 0.26$ & $8.74 \pm 0.17$ \\
\hline $50008.2 \ldots \ldots$ & $12.83 \pm 0.42$ & $9.54 \pm 0.36$ \\
\hline $50044.0 \ldots \ldots$ & $11.60 \pm 0.23$ & $9.66 \pm 0.19$ \\
\hline $50048.6 \ldots \ldots$ & $11.22 \pm 0.37$ & $9.17 \pm 0.35$ \\
\hline $50053.0 \ldots \ldots$ & $10.40 \pm 0.21$ & $9.11 \pm 0.18$ \\
\hline $50061.0 \ldots \ldots$ & $8.64 \pm 0.17$ & $9.27 \pm 0.19$ \\
\hline $50064.6 \ldots \ldots$ & $8.37 \pm 0.28$ & $8.67 \pm 0.33$ \\
\hline $50074.0 \ldots \ldots$ & $8.05 \pm 0.31$ & $7.56 \pm 0.21$ \\
\hline $50075.0 \ldots \ldots$ & $8.18 \pm 0.31$ & $7.35 \pm 0.21$ \\
\hline $50078.0 \ldots \ldots$ & $7.99 \pm 0.30$ & $7.18 \pm 0.20$ \\
\hline $50080.0 \ldots \ldots$ & $7.52 \pm 0.29$ & $7.14 \pm 0.20$ \\
\hline $50081.0 \ldots \ldots$ & $8.25 \pm 0.31$ & $6.80 \pm 0.19$ \\
\hline $50087.0 \ldots \ldots$ & $8.21 \pm 0.16$ & $6.74 \pm 0.14$ \\
\hline $50094.0 \ldots \ldots$ & $8.40 \pm 0.17$ & $6.40 \pm 0.13$ \\
\hline $50095.0 \ldots \ldots$ & $7.88 \pm 0.30$ & $6.40 \pm 0.18$ \\
\hline $50096.0 \ldots \ldots$ & $8.10 \pm 0.31$ & $6.08 \pm 0.17$ \\
\hline $50097.0 \ldots \ldots$ & $8.18 \pm 0.31$ & $6.63 \pm 0.19$ \\
\hline $50098.1 \ldots \ldots$ & $7.76 \pm 0.29$ & $6.82 \pm 0.19$ \\
\hline $50101.9 \ldots \ldots$ & $8.60 \pm 0.17$ & $6.35 \pm 0.13$ \\
\hline $50102.0 \ldots \ldots$ & $8.90 \pm 0.34$ & $6.78 \pm 0.19$ \\
\hline $50104.0 \ldots \ldots$ & $9.39 \pm 0.36$ & $6.72 \pm 0.19$ \\
\hline $50105.0 \ldots \ldots$ & $9.73 \pm 0.37$ & $6.30 \pm 0.18$ \\
\hline $50107.0 \ldots \ldots$ & $9.41 \pm 0.36$ & $6.75 \pm 0.19$ \\
\hline $50108.0 \ldots \ldots$ & $9.50 \pm 0.36$ & $6.75 \pm 0.19$ \\
\hline $50109.0 \ldots \ldots$ & $9.36 \pm 0.36$ & $6.64 \pm 0.19$ \\
\hline $50110.0 \ldots \ldots$ & $9.34 \pm 0.35$ & $6.59 \pm 0.19$ \\
\hline $50111.0 \ldots \ldots$ & $9.82 \pm 0.37$ & $6.81 \pm 0.19$ \\
\hline $50112.0 \ldots \ldots$ & $9.34 \pm 0.35$ & $6.94 \pm 0.19$ \\
\hline $50119.0 \ldots \ldots$ & $10.06 \pm 0.20$ & $7.49 \pm 0.15$ \\
\hline $50122.9 \ldots \ldots$ & $10.04 \pm 0.20$ & $7.67 \pm 0.15$ \\
\hline $50124.0 \ldots \ldots$ & $10.13 \pm 0.38$ & $7.36 \pm 0.21$ \\
\hline $50124.9 \ldots \ldots$ & $10.17 \pm 0.39$ & $7.59 \pm 0.21$ \\
\hline $50126.0 \ldots \ldots$ & $10.27 \pm 0.39$ & $7.86 \pm 0.22$ \\
\hline $50127.6 \ldots \ldots$ & $9.80 \pm 0.22$ & $8.07 \pm 0.16$ \\
\hline $50128.0 \ldots \ldots$ & $10.02 \pm 0.20$ & $7.94 \pm 0.16$ \\
\hline $50128.4 \ldots \ldots$ & $9.81 \pm 0.22$ & $7.82 \pm 0.16$ \\
\hline $50129.0 \ldots \ldots$ & $9.56 \pm 0.36$ & $7.82 \pm 0.22$ \\
\hline $50130.0 \ldots \ldots$ & $9.44 \pm 0.36$ & $8.29 \pm 0.23$ \\
\hline $50131.0 \ldots \ldots$ & $9.78 \pm 0.37$ & $8.20 \pm 0.23$ \\
\hline $50132.0 \ldots \ldots$ & $9.68 \pm 0.37$ & $8.33 \pm 0.23$ \\
\hline $50133.0 \ldots \ldots$ & $10.47 \pm 0.40$ & $8.38 \pm 0.24$ \\
\hline $50134.0 \ldots \ldots$ & $9.02 \pm 0.34$ & $7.77 \pm 0.22$ \\
\hline $50134.9 \ldots \ldots$ & $8.82 \pm 0.34$ & $7.96 \pm 0.22$ \\
\hline $50135.5 \ldots \ldots$ & $9.10 \pm 0.30$ & $7.96 \pm 0.30$ \\
\hline $50136.9 \ldots \ldots$ & $8.86 \pm 0.18$ & $8.12 \pm 0.16$ \\
\hline $50137.0 \ldots \ldots$ & $9.14 \pm 0.35$ & $8.51 \pm 0.24$ \\
\hline $50142.9 \ldots \ldots$ & $8.43 \pm 0.17$ & $8.05 \pm 0.16$ \\
\hline $50149.9 \ldots \ldots$ & $8.45 \pm 0.17$ & $7.22 \pm 0.14$ \\
\hline $50153.6 \ldots \ldots$ & $10.01 \pm 0.50$ & $7.20 \pm 0.36$ \\
\hline $50155.5 \ldots \ldots$ & $9.68 \pm 0.32$ & $6.86 \pm 0.26$ \\
\hline $50156.5 \ldots \ldots$ & $9.96 \pm 0.33$ & $7.20 \pm 0.27$ \\
\hline $50161.5 \ldots \ldots$ & $10.27 \pm 0.34$ & $7.23 \pm 0.28$ \\
\hline $50164.8 \ldots \ldots$ & $10.18 \pm 0.20$ & $7.46 \pm 0.15$ \\
\hline $50168.9 \ldots \ldots$ & $9.88 \pm 0.20$ & $7.75 \pm 0.16$ \\
\hline $50169.0 \ldots \ldots$ & $10.54 \pm 0.40$ & $7.59 \pm 0.21$ \\
\hline $50170.0 \ldots \ldots$ & $10.39 \pm 0.40$ & $7.61 \pm 0.21$ \\
\hline $50175.9 \ldots \ldots$ & $10.86 \pm 0.22$ & $8.12 \pm 0.16$ \\
\hline
\end{tabular}

TABLE 4-Continued

\begin{tabular}{|c|c|c|}
\hline $\begin{array}{c}\text { Julian Date } \\
(-2,400,000)\end{array}$ & $\begin{array}{c}F_{\lambda}(5100 \AA) \\
\left(10^{-15} \operatorname{ergs~s}^{-1} \mathrm{~cm}^{-2} \AA^{-1}\right)\end{array}$ & $\begin{array}{c}F(\mathrm{H} \beta) \\
\left(10^{-13} \mathrm{ergs} \mathrm{s}^{-1} \mathrm{~cm}^{-2}\right)\end{array}$ \\
\hline $50185.9 \ldots \ldots$ & $12.54 \pm 0.25$ & $8.02 \pm 0.16$ \\
\hline $50188.4 \ldots \ldots$ & $12.30 \pm 0.41$ & $8.25 \pm 0.31$ \\
\hline $50191.8 \ldots \ldots$ & $12.07 \pm 0.24$ & $8.55 \pm 0.17$ \\
\hline $50198.8 \ldots \ldots$ & $11.22 \pm 0.22$ & $9.03 \pm 0.18$ \\
\hline $50200.4 \ldots \ldots$ & $10.80 \pm 0.36$ & $9.16 \pm 0.35$ \\
\hline $50201.3 \ldots \ldots$ & $10.49 \pm 0.35$ & $9.06 \pm 0.34$ \\
\hline $50206.9 \ldots \ldots$ & $10.90 \pm 0.22$ & $9.04 \pm 0.18$ \\
\hline $50212.5 \ldots \ldots$ & $10.66 \pm 0.35$ & $9.15 \pm 0.35$ \\
\hline $50212.9 \ldots \ldots$ & $10.31 \pm 0.21$ & $8.71 \pm 0.17$ \\
\hline $50213.4 \ldots \ldots$ & $10.37 \pm 0.34$ & $9.20 \pm 0.35$ \\
\hline $50215.4 \ldots \ldots$ & $10.23 \pm 0.34$ & $9.14 \pm 0.35$ \\
\hline $50220.8 \ldots \ldots$ & $9.21 \pm 0.18$ & $8.73 \pm 0.17$ \\
\hline $50224.4 \ldots \ldots$ & $9.48 \pm 0.31$ & $8.90 \pm 0.34$ \\
\hline $50226.4 \ldots \ldots$ & $10.01 \pm 0.33$ & $8.78 \pm 0.33$ \\
\hline $50227.8 \ldots \ldots$ & $9.17 \pm 0.18$ & $8.39 \pm 0.17$ \\
\hline $50233.8 \ldots \ldots$ & $9.40 \pm 0.19$ & $7.94 \pm 0.16$ \\
\hline $50241.8 \ldots \ldots$ & $9.48 \pm 0.19$ & $7.50 \pm 0.15$ \\
\hline $50245.4 \ldots \ldots$ & $9.92 \pm 0.33$ & $7.67 \pm 0.29$ \\
\hline $50247.4 \ldots \ldots$ & $10.18 \pm 0.34$ & $7.94 \pm 0.30$ \\
\hline $50248.8 \ldots \ldots$ & $10.34 \pm 0.21$ & $7.36 \pm 0.15$ \\
\hline $50253.8 \ldots \ldots$ & $10.89 \pm 0.22$ & $7.43 \pm 0.15$ \\
\hline $50256.5 \ldots \ldots$ & $11.29 \pm 0.37$ & $7.86 \pm 0.30$ \\
\hline $50256.9 \ldots \ldots$ & $11.46 \pm 0.23$ & $7.63 \pm 0.15$ \\
\hline $50258.4 \ldots \ldots$ & $12.04 \pm 0.40$ & $7.80 \pm 0.30$ \\
\hline $50262.8 \ldots \ldots$ & $12.04 \pm 0.24$ & $8.00 \pm 0.16$ \\
\hline $50273.8 \ldots \ldots$ & $12.24 \pm 0.25$ & $9.01 \pm 0.18$ \\
\hline $50276.4 \ldots \ldots$ & $13.82 \pm 0.46$ & $8.58 \pm 0.33$ \\
\hline $50277.4 \ldots \ldots$ & $12.97 \pm 0.43$ & $8.84 \pm 0.34$ \\
\hline $50280.7 \ldots \ldots$ & $13.17 \pm 0.26$ & $7.82 \pm 0.16$ \\
\hline $50284.4 \ldots \ldots$ & $13.43 \pm 0.44$ & $8.93 \pm 0.34$ \\
\hline $50285.4 \ldots \ldots$ & $13.52 \pm 0.45$ & $9.27 \pm 0.35$ \\
\hline $50286.4 \ldots \ldots$ & $13.35 \pm 0.44$ & $9.10 \pm 0.35$ \\
\hline $50305.7 \ldots \ldots$ & $12.11 \pm 0.24$ & $10.03 \pm 0.20$ \\
\hline $50315.3 \ldots \ldots$ & $12.51 \pm 0.41$ & $9.37 \pm 0.36$ \\
\hline $50336.6 \ldots \ldots$ & $13.36 \pm 0.27$ & $9.00 \pm 0.18$ \\
\hline $50339.2 \ldots \ldots$ & $13.75 \pm 0.45$ & $9.46 \pm 0.36$ \\
\hline $50344.2 \ldots \ldots$ & $14.19 \pm 0.47$ & $9.59 \pm 0.36$ \\
\hline $50350.6 \ldots \ldots$ & $14.40 \pm 0.29$ & $8.37 \pm 0.17$ \\
\hline $50358.6 \ldots \ldots$ & $13.93 \pm 0.28$ & $9.44 \pm 0.19$ \\
\hline $50361.6 \ldots \ldots$ & $13.92 \pm 0.28$ & $9.46 \pm 0.19$ \\
\hline $50362.2 \ldots \ldots$ & $14.79 \pm 0.49$ & $9.35 \pm 0.35$ \\
\hline $50372.2 \ldots \ldots$ & $14.48 \pm 0.48$ & $9.39 \pm 0.36$ \\
\hline $50373.2 \ldots \ldots$ & $14.23 \pm 0.47$ & $9.23 \pm 0.35$ \\
\hline
\end{tabular}

The $V$-band measurements obtained from these observations are given in Table 5 , measured by using simulated aperture photometry with a circular aperture of diameter $10^{\prime \prime}$. In each case, the $V$ magnitudes given in column (2) are slightly offset from the continuum measured from the spectroscopic data. The data have been adjusted and converted to fluxes $F_{\lambda}(5100 \AA)$ (as given in col. [4]) using the procedure described in detail by Korista et al. (1995); the systematic corrections employed (eq. [4] of Korista et al.) are $\Delta m=-0.254 \pm 0.048 \mathrm{mag}$ for data set " $\mathrm{A}$ " and $\Delta m=-0.085 \pm 0.050 \mathrm{mag}$ for sets " B " and "C."

The final light curves for the optical continuum and $\mathrm{H} \beta$ fluxes during years 6-8 are shown in Figure 1. The continuum points are from column (2) of Table 3 and column (4) of Table 5, and the $\mathrm{H} \beta$ fluxes are those given in column (3) of Table 3. All measurements are in the observer's frame and are uncorrected for Galactic extinction. 
TABLE 5

$V$-BAND CCD РHOTOMETRY

\begin{tabular}{cccc}
\hline \hline $\begin{array}{c}\text { Julian Date } \\
(-2,400,000) \\
(1)\end{array}$ & $\begin{array}{c}V \\
(\mathrm{mag}) \\
(2)\end{array}$ & $\begin{array}{c}\text { Source } \\
(3)\end{array}$ & $\begin{array}{c}F_{\lambda}(5100 \AA) \\
\left(10^{-15} \mathrm{ergs} \mathrm{s}^{-1} \mathrm{~cm}^{-2} \AA^{-1}\right) \\
(4)\end{array}$ \\
\hline 49458.2 & $13.958 \pm 0.050$ & $\mathrm{~A}$ & $9.90 \pm 0.46$ \\
49459.2 & $13.955 \pm 0.035$ & $\mathrm{~A}$ & $9.90 \pm 0.36$ \\
49460.2 & $14.082 \pm 0.050$ & $\mathrm{~A}$ & $7.92 \pm 0.37$ \\
49460.9 & $13.807 \pm 0.170$ & $\mathrm{~B}$ & $8.78 \pm 1.37$ \\
49461.2 & $14.058 \pm 0.035$ & $\mathrm{~A}$ & $8.36 \pm 0.31$ \\
49462.2 & $14.079 \pm 0.029$ & $\mathrm{~A}$ & $7.93 \pm 0.22$ \\
49463.9 & $13.779 \pm 0.073$ & $\mathrm{~B}$ & $9.23 \pm 0.59$ \\
49703.1 & $13.695 \pm 0.042$ & $\mathrm{C}$ & $10.51 \pm 0.39$ \\
49751.0 & $13.661 \pm 0.068$ & $\mathrm{C}$ & $11.24 \pm 0.72$ \\
49803.9 & $13.548 \pm 0.064$ & $\mathrm{C}$ & $13.21 \pm 0.73$ \\
49851.8 & $13.513 \pm 0.024$ & $\mathrm{C}$ & $14.00 \pm 0.26$ \\
49877.8 & $13.584 \pm 0.046$ & $\mathrm{C}$ & $12.65 \pm 0.58$ \\
49911.8 & $13.682 \pm 0.030$ & $\mathrm{C}$ & $10.86 \pm 0.30$ \\
49952.6 & $13.694 \pm 0.031$ & $\mathrm{C}$ & $10.51 \pm 0.29$ \\
\hline
\end{tabular}

NotE.- Codes for data origin: (A) Yunnan Astronomical Observatory, Kunming, China;(B) $1.0 \mathrm{~m}$ Lick Telescope; (C) $0.61 \mathrm{~m}$ UCLA Telescope.

\section{VARIABILITY ANALYSIS}

The data shown in Figure 1 can be combined with our previously published light curves (Peterson et al. 1991, 1992, 1994; Korista et al. 1995), yielding combined homogeneous light curves that cover a span of 2865 days. The combined data are shown in Figure 2. These light curves are comprised of 857 continuum measurements and 820 line measurements. The number of spectra in this database exceeds by more than a factor of 4 the number of spectra in any other homogeneous time series on UV or optical variations in Seyfert galaxies (see Wanders et al. 1997; Peterson et al. 1998a), and previous less well-sampled and less homogenous data extend the database on this object to $20 \mathrm{yr}$ (Sergeev et al. 1997). In this section, we will summarize the basic characteristics of the $8 \mathrm{yr}$ homogeneous database, both in its entirety and on a year-by-year basis.

\subsection{Characteristics of the Database}

Tables 6 and 7 provide a summary for the continuum and $\mathrm{H} \beta$ emission line, respectively, of the basic characteristics of the light curves of NGC 5548, broken down into subsets of time, as given in column (1). The number of observations in the subset is given in column (2), and columns (3) and (4)

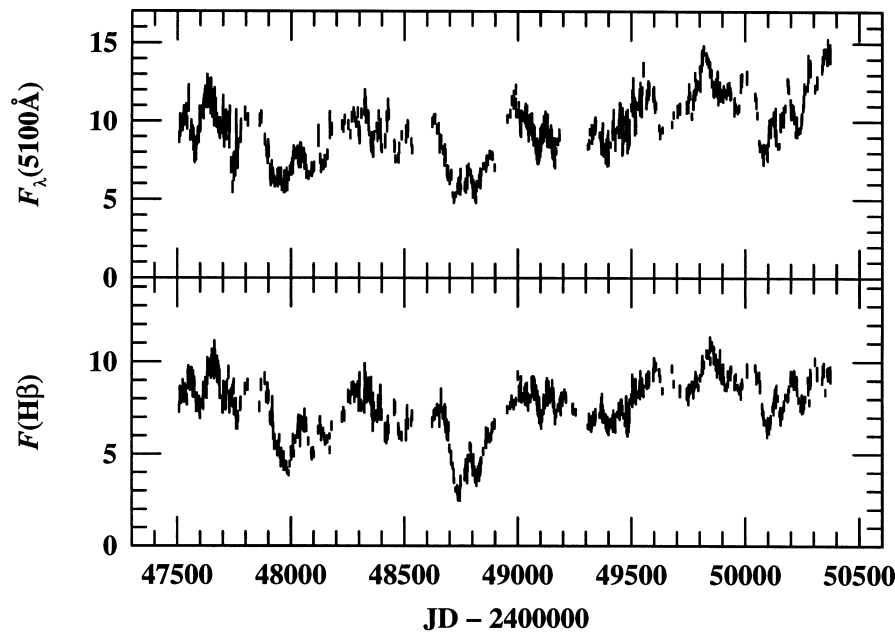

FIG. 2.-Optical continuum (upper panel) and $\mathrm{H} \beta$ (lower panel) light curves from 1989 December to 1996 November. The data are comprised of 857 continuum measurements and 820 emission-line measurements. The continuum fluxes are in units of $10^{-15} \mathrm{ergs} \mathrm{s}^{-1} \mathrm{~cm}^{-2} \AA^{-1}$, and the line fluxes are in units of $10^{-13} \mathrm{ergs} \mathrm{s}^{-1} \mathrm{~cm}^{-2}$.

give the average and median intervals, respectively, between successive observations. Note that for the entire data set, the relatively large ratio of the average to the median is attributable to the 1-2 month gaps between observing seasons. The mean and root mean square (rms) fluxes, $F_{\lambda}(5100 \AA)$ in Table 6 and $F(\mathrm{H} \beta)$ in Table 7 , are given in column (5). Two standard measures of variability, $F_{\text {var }}$ and $R_{\max }$, are given in columns (6) and (7), respectively. The parameter $F_{\text {var }}$ is the rms fractional variability, corrected for measurement error, as defined by Rodríguez-Pascual et al. (1997), and $R_{\max }$ is simply the ratio of maximum to minimum flux. Both of these parameters are affected by contamination of the measured quantities by constant-flux components, the underlying host galaxy in the case of the continuum, and the narrow $\mathrm{H} \beta$ emission component in the case of the line. The continuum flux measurements are all adjusted to a standard entrance aperture of $5.0 \times 7 " .5$, through which the starlight component can be estimated to contribute $V_{\text {galaxy }}=14.99 \mathrm{mag}$, or $F_{\lambda}(5100 \AA)_{\text {galaxy }}=$ $3.4 \times 10^{-15} \mathrm{ergs} \mathrm{s}^{-1} \mathrm{~cm}^{-2} \AA^{-1}$ (Romanishin et al. 1995). Subtracting this value from all the continuum points in Figure 2 increases $F_{\text {var }}$ from 0.195 to 0.307 and $R_{\max }$ from

TABLE 6

SAmpling Statistics for Optical ContinuUm

\begin{tabular}{|c|c|c|c|c|c|c|}
\hline \multirow[b]{2}{*}{$\begin{array}{l}\text { SUBSET } \\
\text { (1) }\end{array}$} & \multirow[b]{2}{*}{$\begin{array}{l}\text { NUMBER OF EPOCHS } \\
\text { (2) }\end{array}$} & \multicolumn{2}{|c|}{ SAMPLING INTERVAL (days) } & \multirow[b]{2}{*}{$\begin{array}{c}\text { Mean Flux } \\
\text { (5) }\end{array}$} & \multirow[b]{2}{*}{$\begin{array}{l}F_{\mathrm{var}} \\
(6)\end{array}$} & \multirow[b]{2}{*}{$\begin{array}{l}R_{\max } \\
\text { (7) }\end{array}$} \\
\hline & & $\begin{array}{l}\text { Average } \\
\text { (3) }\end{array}$ & $\begin{array}{l}\text { Median } \\
\text { (4) }\end{array}$ & & & \\
\hline All data & 857 & 3.3 & 1.0 & $9.35 \pm 1.86$ & 0.195 & $2.98 \pm 0.16$ \\
\hline Year 1 (1989) & 125 & 2.4 & 1.0 & $9.92 \pm 1.26$ & 0.117 & $2.16 \pm 0.16$ \\
\hline Year $2(1990)$ & 94 & 3.4 & 2.0 & $7.25 \pm 1.00$ & 0.129 & $1.82 \pm 0.09$ \\
\hline Year 3 (1991) & 65 & 4.8 & 3.0 & $9.40 \pm 0.93$ & 0.090 & $1.51 \pm 0.09$ \\
\hline Year 4 (1992) & 83 & 3.4 & 2.0 & $6.72 \pm 1.17$ & 0.168 & $2.04 \pm 0.10$ \\
\hline Year 5 (1993) & 174 & 1.3 & 0.7 & $9.04 \pm 0.90$ & 0.092 & $1.65 \pm 0.08$ \\
\hline Year 6 (1994) & 135 & 2.4 & 1.0 & $9.76 \pm 1.10$ & 0.104 & $1.76 \pm 0.12$ \\
\hline Year 7 (1995) & 83 & 4.0 & 1.9 & $12.09 \pm 1.00$ & 0.079 & $1.48 \pm 0.04$ \\
\hline Year 8 (1996) & 98 & 3.4 & 2.0 & $10.47 \pm 1.82$ & 0.171 & $1.97 \pm 0.10$ \\
\hline
\end{tabular}

\footnotetext{
${ }^{\text {a }}$ Units of $10^{-15} \mathrm{ergs} \mathrm{s}^{-1} \mathrm{~cm}^{-2} \AA^{-1}$.
} 
TABLE 7

SAmpling Statistics for H $\beta$ Emission Line

\begin{tabular}{|c|c|c|c|c|c|c|}
\hline \multirow[b]{2}{*}{$\begin{array}{l}\text { SUBSET } \\
\text { (1) }\end{array}$} & \multirow[b]{2}{*}{$\begin{array}{l}\text { NuMBER OF EPOCHS } \\
\text { (2) }\end{array}$} & \multicolumn{2}{|c|}{ SAMPLING INTERVAL (days) } & \multirow[b]{2}{*}{$\begin{array}{c}\text { MEAn Flux }{ }^{\mathrm{a}} \\
\text { (5) }\end{array}$} & \multirow[b]{2}{*}{$\begin{array}{l}F_{\text {var }} \\
(6)\end{array}$} & \multirow[b]{2}{*}{$\begin{array}{l}R_{\max } \\
\text { (7) }\end{array}$} \\
\hline & & $\begin{array}{l}\text { Average } \\
\text { (3) }\end{array}$ & $\begin{array}{l}\text { Median } \\
\text { (4) }\end{array}$ & & & \\
\hline All data.. & 820 & 3.5 & 1.4 & $7.56 \pm 1.53$ & 0.199 & $4.17 \pm 0.30$ \\
\hline Year 1 (1989)...... & 132 & 2.3 & 1.0 & $8.62 \pm 0.85$ & 0.091 & $1.57 \pm 0.12$ \\
\hline Year $2(1990) \ldots \ldots$ & 94 & 3.4 & 2.0 & $5.98 \pm 1.17$ & 0.191 & $2.30 \pm 0.12$ \\
\hline Year 3 (1991)..... & 65 & 4.8 & 3.0 & $7.46 \pm 0.81$ & 0.093 & $1.58 \pm 0.14$ \\
\hline Year 4 (1992)...... & 83 & 3.4 & 2.0 & $4.96 \pm 1.44$ & 0.284 & $3.03 \pm 0.30$ \\
\hline Year 5 (1993)...... & 142 & 2.1 & 1.0 & $7.93 \pm 0.53$ & 0.057 & $1.40 \pm 0.06$ \\
\hline Year 6 (1994)..... & 128 & 2.6 & 1.0 & $7.58 \pm 0.94$ & 0.117 & $1.57 \pm 0.07$ \\
\hline Year 7 (1995)...... & 78 & 4.2 & 2.1 & $9.27 \pm 0.70$ & 0.071 & $1.38 \pm 0.06$ \\
\hline Year $8(1996) \ldots \ldots$ & 98 & 3.4 & 2.0 & $8.03 \pm 0.96$ & 0.116 & $1.65 \pm 0.06$ \\
\hline
\end{tabular}

${ }^{a}$ Units of $10^{-13} \mathrm{ergs} \mathrm{s}^{-1} \mathrm{~cm}^{-2}$.

$2.98 \pm 0.16$ to $7.26 \pm 0.98$; i.e., the AGN nuclear continuum has varied by more than a factor of 7 in 8 yr. Similarly, we can estimate that the narrow $\mathrm{H} \beta$ contribution to the line measurements is about $8.43 \times 10^{-14}$ ergs $\mathrm{s}^{-1} \mathrm{~cm}^{-2}$ (Wanders \& Peterson 1996). Subtracting this from the line measurements yields $F_{\text {var }}=0.224$ and $R_{\max }=5.67 \pm 0.56$ for the broad $\mathrm{H} \beta$ component.

During year 7, NGC 5548 achieved the highest luminosity state we have observed. The faintest state observed was during year 4. In Figure 3, we show set " $H$ " spectra obtained near the times of extreme states. Note in particular the dramatic difference in the continuum levels shortward of about $4200 \AA$, the onset of the Balmer continuum and Fe II emission-line blend referred to as the "small blue bump" (see Maoz et al. 1993 for a discussion of the variability of the small blue bump in NGC 5548). The low-state spectrum in Figure 3 shows that the narrow-line components of the Balmer lines are quite strong; the high-state spectrum is in fact strongly double-peaked, but the central depression is largely filled in by the narrow component.

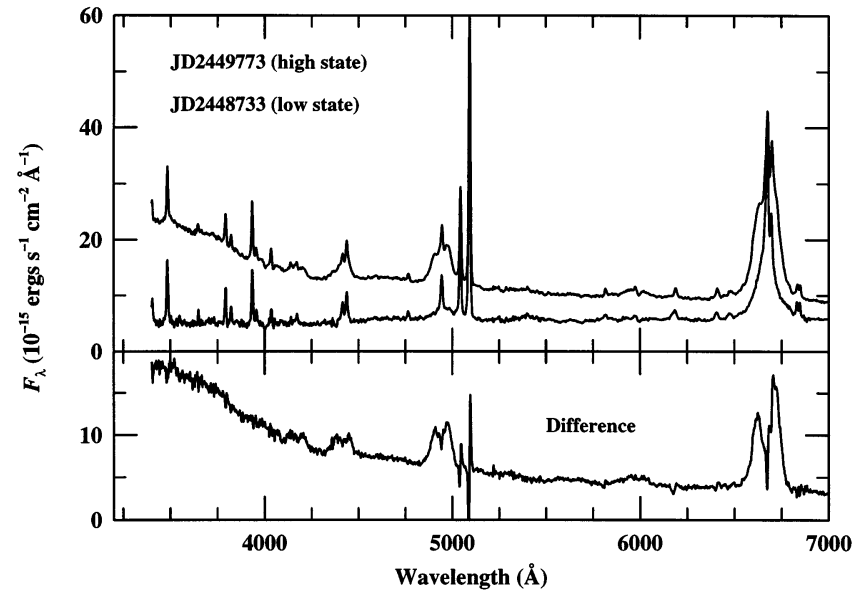

FIG. 3.-Upper panel: high-state (JD 2,449,773, during 1995) and lowstate (JD 2,448,733, during 1992) Lick Observatory (set " $\mathrm{H}$ ") spectra of NGC 5548 showing extreme excursions of the continuum brightness. Lower panel: difference spectrum obtained by subtracting the low-state spectrum from the high-state spectrum. In the low-state spectrum, the broad component of $\mathrm{H} \beta$ (just shortward of $5000 \AA$ ) is very weak, and the constant narrow-line component is thus relatively more prominent than when the broad component is strong. The most dramatic effect is the variability of the "small blue bump," the long-wavelength end of which is apparent in the high-state spectrum shortward of $\sim 4200 \AA$.
This is why the double-peaked structure of the broad lines is much more prominent in the difference spectrum than in the high-state spectrum.

\subsection{Time-Series Analysis}

Inspection of Figure 1 shows that there is a clear time delay between continuum variations and the $\mathrm{H} \beta$ response. This time delay can be quantified by cross-correlation of the continuum and emission-line light curves. We perform the cross-correlation analysis in two ways, using the interpolation cross-correlation function (ICCF) method of Gaskell \& Sparke (1986) and Gaskell \& Peterson (1987) and the discrete correlation function (DCF) method of Edelson $\&$ Krolik (1988). In both cases, we use the implementation described by White \& Peterson (1994).

The results of the cross-correlation analysis are shown in Figure 4 and summarized in Table 8 . In Table 8, the subset used in cross-correlation is given in column (1). Column (2) gives the centroid $\tau_{\text {cent }}$ of the ICCF. The highest point in the ICCF occurs at a time delay $\tau_{\text {peak }}$ (col. [3]) and has value $r_{\text {max }}$ (col. [4]). The FWHM of the ICCF is given in column (5). The centroid $\tau_{\text {cent }}$ is computed using all points near $\tau_{\text {peak }}$ with values greater than $0.8 r_{\max }$. The uncertainties quoted for $\tau_{\text {cent }}$ and $\tau_{\text {peak }}$ have been computed using the modelindependent FR/RSS Monte Carlo method described by Peterson et al. (1998b).

\section{DISCUSSION}

It is apparent from inspection of Table 8 that significant changes in the $\mathrm{H} \beta$ lag have occurred during this $8 \mathrm{yr}$ monitoring program. The cross-correlation functions shown in Figure 4 show pronounced changes from year to year. The centroid $\tau_{\text {cent }}$ is of particular interest, because it is a measure of the responsivity-weighted mean radius of the BLR (Koratkar \& Gaskell 1991; Penston 1991). Possible changes in the $\mathrm{H} \beta$ lag have been noticed previously and might plausibly arise in a number of ways:

1. A physically thick BLR has a broad transfer function, and the centroid convolution of $\Psi(\tau)$ and $F_{\mathrm{ACF}}(\tau)$ can become quite sensitive to the general character of the continuum variations as embodied in the ACF (Netzer \& $\mathrm{MaOz}$ 1990).

2. Real dynamical changes in the BLR might occur on timescales of years (Wanders 1995). This has also been suggested to be the case in NGC 4151 (e.g., Ulrich et al. 1991). 


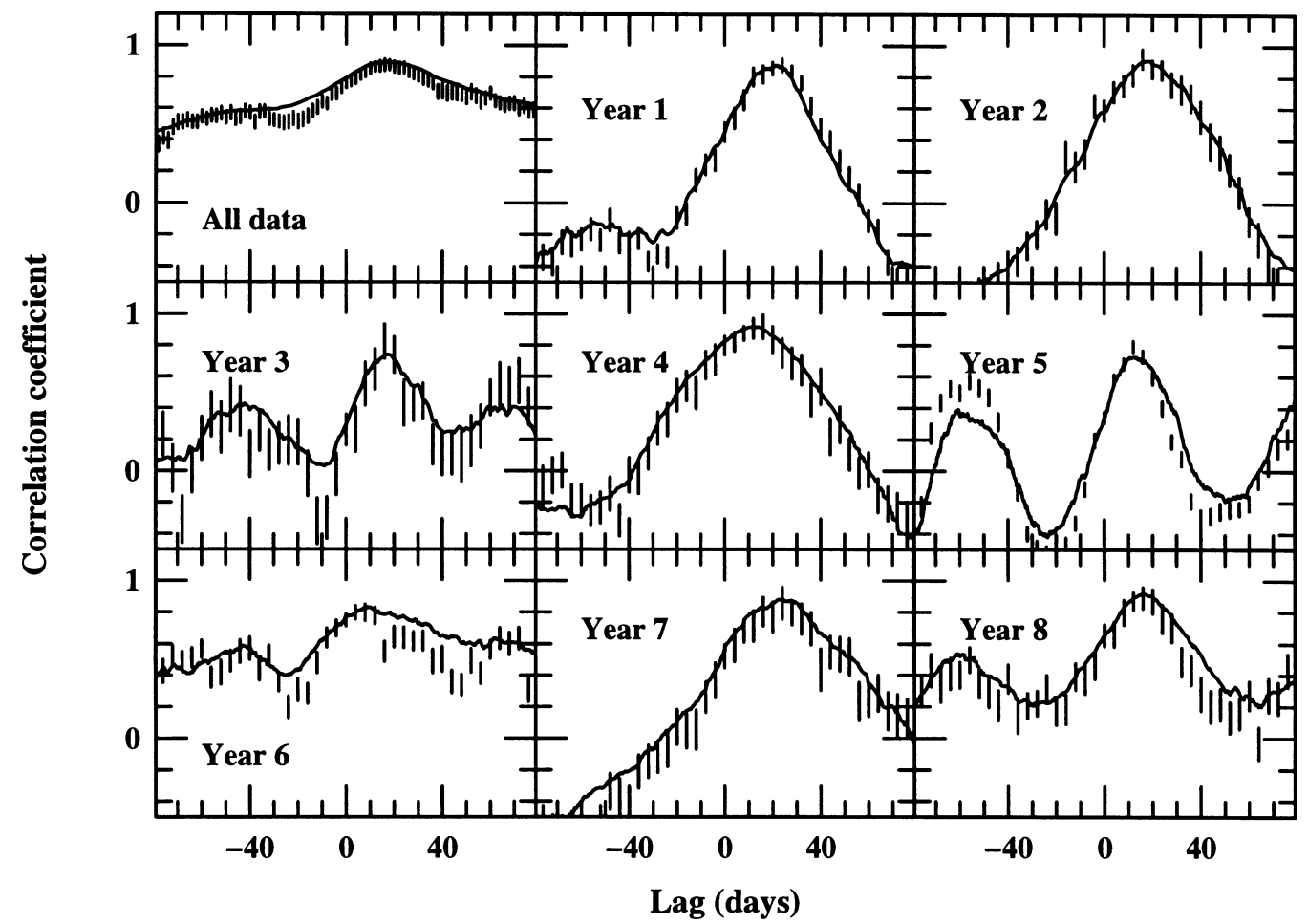

FIG. 4.-Cross-correlation functions for the continuum and $\mathrm{H} \beta$ emission-line light curves of NGC 5548. The various panels represent subsets of the data as outlined in Table 8. The solid line shows the ICCF, and the vertical lines represent the $1 \sigma$ uncertainties associated with the DCF values.

3. The lag might vary with the ionizing flux incident upon the BLR clouds. For BLR clouds with otherwise constant parameters, the radius at which emissivity in a particular line is optimized will be dependent on the luminosity of the source (e.g., Baldwin et al. 1995).

In Figure 5, we show in the upper panel $\tau_{\text {cent }}$ as a function of time for the $8 \mathrm{yr}$ of International AGN Watch data

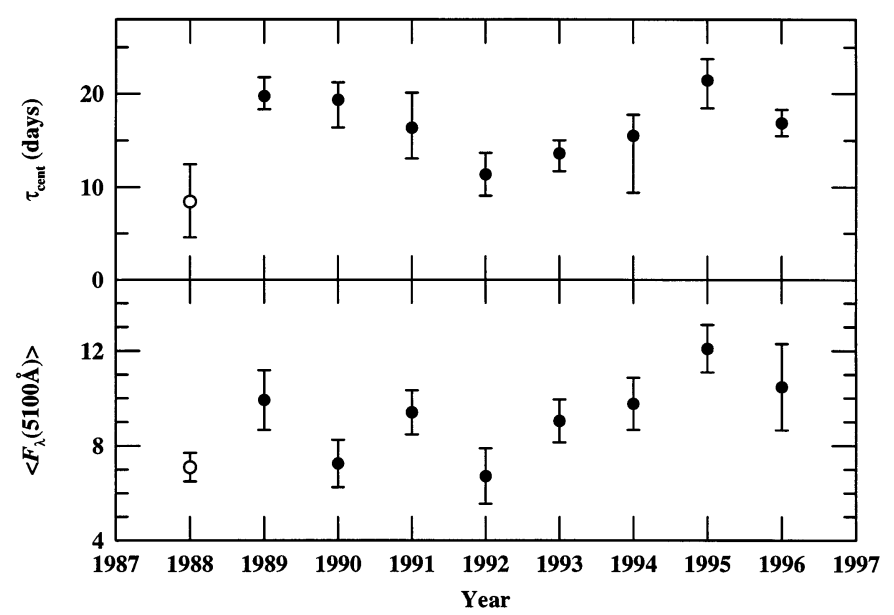

FIG. 5.-Upper panel: Cross-correlation centroid $\tau_{\text {cent }}$ as a function of time for 9 yr beginning with 1988 (from the Wise Observatory campaign described by Netzer et al. 1990; open circle), followed by the 8 yr of International AGN Watch monitoring ( filled circles). Lower panel: Early mean continuum flux at $5100 \AA$. The error bars simply represent the rms variations about the mean values. reported here, plus the results of the 1988 monitoring program carried out at Wise Observatory ${ }^{20}$ (Netzer et al. 1990). This bears some resemblance to the light curve averaged over individual observing seasons, as shown in the lower panel of the figure, suggesting that the lag may be a

TABLE 8

Cross-Correlation Results

\begin{tabular}{|c|c|c|c|c|}
\hline $\begin{array}{l}\text { Subset } \\
\text { (1) }\end{array}$ & $\begin{array}{c}\tau_{\text {cent }} \\
\text { (days) } \\
(2)\end{array}$ & $\begin{array}{c}\tau_{\text {peak }} \\
\text { (days) } \\
(3)\end{array}$ & $\begin{array}{c}r_{\max } \\
\text { (4) }\end{array}$ & $\begin{array}{c}\text { FWHM } \\
\text { (days) } \\
(5)\end{array}$ \\
\hline All data ............ & $21.57_{-0.68}^{+2.41}$ & $16.5_{-1.1}^{+2.1}$ & 0.896 & 199 \\
\hline Year 1 (1989)...... & $19.73_{-1.40}^{+2.03}$ & $21.5_{-4.1}^{+3.0}$ & 0.877 & 39 \\
\hline Year $2(1990) \ldots \ldots$ & $19.34_{-2.96}^{+1.86}$ & $18.5_{-0.7}^{+2.0}$ & 0.909 & 49 \\
\hline Year $3(1991) \ldots \ldots$ & $16.35_{-3.28}^{+3.75}$ & $17.5_{-5.7}^{+2.7}$ & 0.740 & 33 \\
\hline Year 4 (1992)...... & $11.37_{-2.30}^{+2.30}$ & $13.7_{-4.7}^{+0.6}$ & 0.918 & 63 \\
\hline Year 5 (1993)...... & $13.61_{-1.91}^{+1.41}$ & $13.2_{-3.3}^{+1.9}$ & 0.730 & 29 \\
\hline Year $6(1994) . . . .$. & $15.49_{-6.09}^{+2.26}$ & $8.7_{-2.4}^{+8.5}$ & 0.832 & 129 \\
\hline Year 7 (1995)...... & $21.43_{-3.00}^{+2.31}$ & $22.9_{-3.1}^{+5.4}$ & 0.880 & 60 \\
\hline Year $8(1996) . . . .$. & $16.85_{-1.37}^{+1.45}$ & $16.3_{-1.5}^{+1.1}$ & 0.921 & 51 \\
\hline
\end{tabular}

${ }^{20}$ We have adjusted the Wise Observatory data to form as nearly as possible a quasi-homogeneous set with the International AGN Watch data. Through simulated aperture photometry based on the nucleus-free image described by Romanishin et al. (1995), we estimate that the starlight contribution through the Wise Observatory entrance aperture is $1.166 \times 10^{-14} \mathrm{ergs} \mathrm{s}^{-1} \mathrm{~cm}^{-2} \AA^{-1}$. The 5375-5575 $\AA$ fluxes of Netzer et al. (1990) have been adjusted to the nominal galaxy contribution in the AGN Watch data, $3.4 \times 10^{-15} \mathrm{ergs} \mathrm{s}^{-1} \mathrm{~cm}^{-2} \AA^{-1}$. The cross-correlation methodology used in this paper gives $\tau_{\text {cent }}=8.44_{-3.87}^{+4.01}$ for the Wise Observatory campaign. 


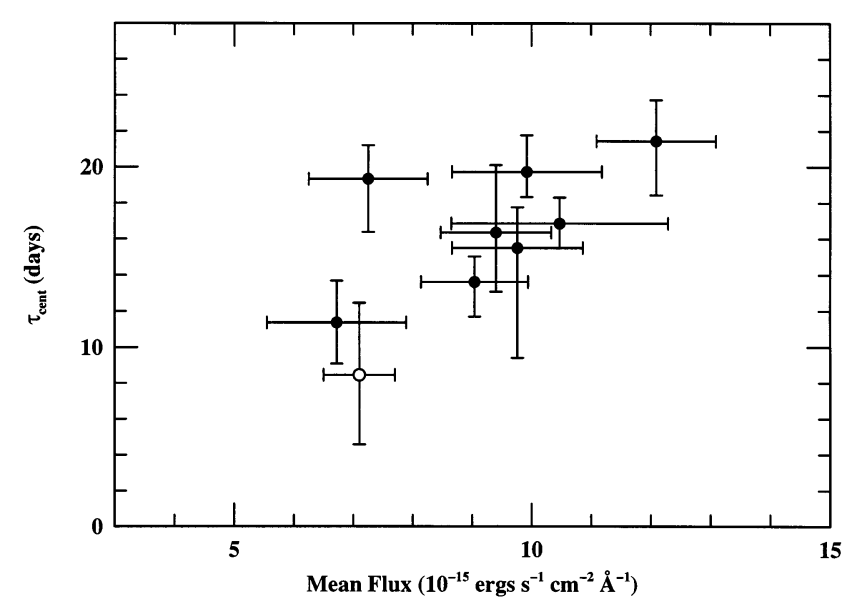

FIG. 6.-Cross-correlation centroid $\tau_{\text {cent }}$ as a function the yearly mean continuum flux at $5100 \AA$, based on 8 yr of International AGN Watch data ( filled circles) plus 1988 data from Wise Observatory (open circle). The data suggest that these two quantities may be correlated, and the slope of the best-fit line is nonzero only at a $2.5 \sigma$ confidence level.

luminosity-dependent quantity. In Figure 6, we plot directly $\tau_{\text {cent }}$ as a function $\left\langle F_{\lambda}(5100 \AA)\right\rangle$, the mean continuum flux. Again, this suggests a relationship between these quantities. The slope of this relationship is formally nonzero at $2.5 \sigma$ significance.

\section{SUMMARY}

We have presented new optical spectroscopic and photometric observations of the continuum and $\mathrm{H} \beta$ emission-line variations in the Seyfert 1 galaxy NGC 5548, thus extending our high-intensity coverage of this object to $8 \mathrm{yr}$. The total continuum light curve consists of 857 epochs and the $\mathrm{H} \beta$ light curve consists of 825 epochs. We find as before that the variations of the $\mathrm{H} \beta$ emission line follow those of the continuum by $\sim 10-20$ days, with the precise value of the measured lag changing somewhat from year to year. There are indications that the lag varies with the continuum flux in the sense that the lag is larger when the continuum is brighter.

We are grateful to the Directors and Telescope Allocation Committees of our various observatories for their support of this project. Individual investigators have benefited from the support from a number of grants, including the following: National Science Foundation grants AST 94-20080 (Ohio State University) and AST 94-17213 (University of California at Berkeley), Sonderforschungsbereich grant 328 (Landessternwarte Heidelberg), DFG grant Ko 857/13-2 (Universitäts-Sternwarte Göttingen), the Russian Basic Research Foundation grants 94-02-4885 and 97-02-17625, and the PanDen Project of the Chinese National Committee of Sciences and the Chinese National Science Foundation.

\section{REFERENCES}

Alloin, D., Clavel, J., Peterson, B. M., Reichert, G. A., \& Stirpe, G. M. 1994, in Frontiers of Space and Ground-Based Astronomy, ed. W. Wamsteker, M. S. Longair, \& Y. Kondo (Dordrecht: Kluwer), 423 Baldwin, J., Ferland, G., Korista, K., \& Verner, D. 1995, ApJ, 455, L119

Blandford, R. D., \& McKee, C. F. 1982, ApJ, 255, 419

Clavel, J., et al. 1991, ApJ, 366, 64

Edelson, R. A., \& Krolik, J. H. 1988, ApJ, 333, 646

Fabricant, D., Cheimets, P., Caldwell, N., \& Geary, J. 1998, PASP, 110, 79

Gaskell, C. M., \& Peterson, B. M. 1987, ApJS, 65, 1

Gaskell, C. M., \& Sparke, L. S. 1986, ApJ, 305, 175

Koratkar, A. P., \& Gaskell, C. M. 1991, ApJS, 75, 719

Korista, K. T., et al. 1995, ApJS, 97, 285

Kraemer, S. B., Crenshaw, D. M., Filippenko, A. V., \& Peterson, B. M. 1998, ApJ, 498, 719

Maoz, D., et al. 1993, ApJ, 404, 576

Marshall, H. L., et al. 1997, ApJ, 479, 222

Netzer, H., \& Maoz, D. 1990, ApJ, 365, L5

Netzer, H., et al. 1990, ApJ, 353, 108

Netzer, H., \& Peterson, B. M. 1997, in Astronomical Time Series, ed.

D. Maoz, A. Sternberg, \& E. M. Leibowitz (Dordrecht: Kluwer), 85

Penston, M. V. 1991, in Variability of Galactic Nuclei, ed. H. R. Miller \&

P. J. Wiita (Cambridge: Cambridge Univ. Press), 343

Peterson, B. M. 1993, PASP, 105, 247

Peterson, B. M., et al. 1991, ApJ, 368, 119 1992, ApJ, 392, 470 1994, ApJ, 425, 622

Peterson, B. M., Pogge, R. W., Wanders, I., Smith, S. M., \& Romanishin, W. 1995, PASP, 107,579

Peterson, B. M., Wanders, I., Bertram, R., Hunley, J. F., Pogge, R. W., \& Wagner, R. M. 1998a, ApJ, 501, 82

Peterson, B. M., Wanders, I., Horne, K., Collier, S., Alexander, T., Kaspi, S., \& Maoz, D. 1998b, PASP, 110, 660

Rodríguez-Pascual, P. M., et al. 1997, ApJ, 110, 9

Romanishin, W., et al. 1995, ApJ, 455, 516

Sergeev, S. G., Pronik, V. I., Malkov, Yu. F., \& Chuvaev, K. K. 1997, A\&A, 320,405

Ulrich, M.-H., Boksenberg, A., Bromage, G. E., Clavel, J., Elvius, A.,

Penston, M. V., Perola, G. C., \& Snijders, M. A. J. 1991, ApJ, 382, 483

van Groningen, E., \& Wanders, I. 1992, PASP, 104, 700

Wanders, I. 1995, A\&A, 296, 332

Wanders, I., \& Peterson, B. M. 1996, ApJ, 466, 174

Wanders, I., et al. 1997, ApJS, 113, 69

White, R. J., \& Peterson, B. M. 1994, PASP, 106, 879 